\title{
RSV Infection Promotes Necroptosis and HMGB1 Release by Airway Epithelial Cells
}

Jennifer Simpson ${ }^{1,2}$, Zhixuan Loh², Md Ashik Ullah ${ }^{1,2}$, Jason P. Lynch ${ }^{1,2}$, Rhiannon B. Werder $^{1,2}$, Natasha Collinson ${ }^{1}$, Vivian Zhang ${ }^{1,2}$, Yves Dondelinger ${ }^{3,4}$, Mathieu J.M.

Bertrand $^{3,4}$, Mark L. Everard 5 , Christopher C. Blyth ${ }^{5-8}$, Gunter Hartel ${ }^{1}$, Antoon J. Van Oosterhout $^{9}$, Peter J. Gough ${ }^{10}$, John Bertin ${ }^{10}$, John W. Upham ${ }^{11,12}$, Kirsten M. Spann ${ }^{13 *}$, Simon Phipps ${ }^{1,2,12, *}$

1. QIMR Berghofer Medical Research Institute, Herston, QLD, Australia

2. School of Biomedical Science, University of Queensland, QLD, Australia.

3. VIB Centre for Inflammation Research, 9052, Ghent, Belgium

4. Department of Biomedical Molecular Biology, Ghent University, 9052, Ghent, Belgium

5. School of Medicine, University of Western Australia, Perth, Australia

6. Department of Infectious Diseases, Perth Children's Hospital, Perth, Australia

7. Department of Microbiology, PathWest Laboratory Medicine WA, QEII Medical Centre, Perth, Australia

8. Wesfarmers Centre for Vaccines and Infectious Diseases, Telethon Kids Institute, University of Western Australia, Perth, Australia;

9. GlaxoSmithKline, Stevenage, UK

10. GlaxoSmithKline, Pennsylvania, USA

11. University of Queensland Diamantina Institute, Brisbane, QLD, Australia

12. Australian Infectious Diseases Research Centre, QLD, Australia. 
13. Queensland University of Technology, Brisbane, QLD, Australia.

Corresponding author: Simon Phipps (Simon.Phipps@qimrberghofer.edu.au)

We acknowledge financial support from ARC Australia (S.P.), NHMRC Australia (S.P.), GlaxoSmithKline (S.P.), and Fonds voor Wetenschappelijk Onderzoek Vlaanderen (M.J.M.B and Y.D.). S.P. and A.J.V.O conceived the idea for the project. S.P and J.S designed the experiments. S.P, J.S and K.S interpreted the data and wrote the first draft of the manuscript, and all remaining authors edited to generate the final version. J.S, Z.L, J.P.L, R.B.W, N.C, V.Z and A.U performed the experiments. Y.D, M.B, P.J.G, A.J.V.O, J.B, M.L.E, C.C.B, G.H, J.W.U and K.S. provided intellectual input and reagents.

Running head: RSV bronchiolitis and airway epithelial necroptosis.

Descriptor number: 7.18 Mucosal Immunity of the Respiratory Tract

Word Count: 3500

This article has an online data supplement, which is accessible from this issue's table of content online at www.atsjournals.org

* Contributed equally 


\begin{abstract}
Rationale:

RSV bronchiolitis causes significant infant mortality. Bronchiolitis is characterised by airway epithelial cell (AEC) death, however the mode of death remains unknown.
\end{abstract}

\title{
Objectives:
}

To determine whether necroptosis contributes to RSV bronchiolitis pathogenesis via high mobility group box 1 (HMGB1) release.

\section{Methods:}

Nasopharyngeal samples were collected from children presenting to hospital with acute respiratory infection. Primary human AECs and neonatal mice were inoculated with RSV and murine pneumovirus respectively. Necroptosis was determined via viability assays and immunohistochemistry for receptor-interacting protein kinase-1 (RIPK1), mixed lineage kinase domain-like protein (MLKL) and caspase-3. Necroptosis was blocked using pharmacological inhibitors, and RIPK1 kinase-dead knock-in mice.

\section{Measurements and Main Results:}

HMGB1 levels were elevated in nasopharyngeal samples of children with acute RSV infection. RSV-induced epithelial cell death was associated with increased pRIPK1 and pMLKL, but not active caspase-3 expression. Inhibition of RIPK1 or MLKL attenuated RSVinduced HMGB1 translocation and release, and lowered viral load. MLKL inhibition increased active caspase-3 expression in a caspase-8/9-dependent manner. In susceptible mice, Pneumovirus infection up-regulated RIPK1 and MLKL expression in the airway epithelium at 8-10 days post infection; coinciding with AEC sloughing, HMGB1 release, and 
neutrophilic inflammation. Genetic or pharmacological inhibition of RIPK1 or MLKL attenuated these pathologies, lowered viral load, and prevented type- 2 inflammation and airway remodeling. Necroptosis inhibition in early-life ameliorated asthma progression induced by viral or allergen challenge in later-life.

\section{Conclusions:}

Pneumovirus infection induces AEC necroptosis. Inhibition of necroptosis may be a viable strategy to limit the severity of viral bronchiolitis and break its nexus with asthma.

Word count: 250

MeSH key words: Bronchiolitis, asthma, MLKL, Pneumovirus, necroptosis 


\section{Introduction}

Respiratory syncytial virus (RSV)-induced bronchiolitis is associated with significant mortality worldwide (1). Additionally, severe RSV bronchiolitis in infancy is associated with subsequent airways disease including asthma (2-4). In the absence of an approved vaccine for RSV, new treatments that effectively manage and reduce RSV-associated pathogenesis are urgently needed. Pathologically, severe bronchiolitis is characterised by neutrophilic inflammation, mucus hypersecretion, and airway epithelial cell (AEC) sloughing $(5,6)$. These dead epithelial cells, together with a viscous exudate, can form dense plugs in the bronchiolar lumen that impede breathing $(6,7)$. Despite this, the prevailing view is that AEC death is a beneficial defense mechanism, limiting viral spread.

Host defense to viral infection depends on the activation of innate pattern recognition receptors, which induce the production of antiviral cytokines such as type I and III IFNs. In turn, these cytokines initiate the antiviral state to restrict virus replication and spread, and promote the activation of NK cells and cytotoxic T lymphocytes (CTLs) that ultimately clear the virus by inducing apoptotic death of infected cells (8). Genetic and/or environmental factors that perturb the successful coordination of this response predispose toward severe RSV bronchiolitis (9-11). To model the immunopathology and sequelae, we developed a preclinical gene-environment model by inoculating interferon regulatory factor 7 (IRF7)deficient mice with PVM, a mouse Pneumovirus and homolog of RSV. As a consequence of impaired antiviral immunity, these mice develop severe epithelial sloughing, leading to HMGB1 release and neutrophilic inflammation in early-life, and are predisposed to asthma in later-life (unpublished observations). Critically, HMGB1 neutralisation ablated all of these events.

HMGB1 is a chromatin-binding protein that can be released into the extracellular space to 
function as a pro-inflammatory cytokine. As a consequence, its release and activation state is highly controlled. Cellular mechanisms known to regulate HMGB1 release include vesicular transport, inflammasome activation, necrosis, and necroptosis (12-15). This recently identified form of programmed cell death is initiated by the formation of a multi-protein complex termed the necrosome (16), which typically contains phosphorylated RIPK1 (pS166) and pRIPK3, leading to the phosphorylation of $\operatorname{MLKL}(13,14,17,18)$. In contrast to apoptosis, necroptosis most commonly elicits a pro-inflammatory response, in keeping with its role in mediating HMGB1 release, and can delay viral clearance (19). This led us to question the current dogma that the induction of AEC death during RSV bronchiolitis serves to restrict virus spread and limit host immunopathology. Specifically, we interrogated the mode of RSV-associated AEC death and downstream HMGB1 release using human and mouse primary AECs in culture. To support our in vitro findings, we evaluated the mechanism of AEC sloughing and HMGB1 release, and the effect of necroptosis inhibition, in our preclinical model of severe viral bronchiolitis and later experimental asthma.

\section{Materials and Methods.}

\section{Human subjects and nasopharyngeal samples.}

Samples were prospectively collected from 2-year-old children (IQ range 1.25 to 3.86) presenting with acute respiratory infection to the Princess Margaret Hospital, Perth. Ethical approval was obtained from the ethics committees of Princess Margaret Hospital for Children (1673/EP), the South Metropolitan Area Health Service, and the Western Australian Aboriginal Health Information and Ethics Committee. All samples were frozen at $-80^{\circ} \mathrm{C}$ prior to the measurement of HMGB1 by ELISA (Chondrex, Redmond, WA, US). The presence of respiratory viruses was tested by polymerase chain reaction (PCR) assay. 


\section{hAEC culture and treatment}

Human AECs from healthy paediatric (age 2-3 years) donors (ID 28195, 28563, 28385, and 29055) were obtained commercially (Lonza). Purified RSV A2 stocks were prepared as previously described (20). Non-differentiated (submerged) or air-liquid interface (ALI)differentiated AECs were grown and infected with RSV as previously described $(21,22)$. One hour prior to RSV infection, the cells were pre-treated with a pRIPK1 inhibitor (Necrostatin 1s; Nec-1s, $2.2 \mu \mathrm{M}$; Biovision) (23), which reduces RIPK1 phosphorylation, an MLKL inhibitor (necrosulfonamide; NSA; $10 \mu \mathrm{M}$; Merck) (24), which prevents MLKL translocation to the plasma membrane, a caspase-9 inhibitor (Z-LEHD-FMK; $2 \mu \mathrm{M}$; Biovision), and/or a caspase-8 inhibitor (Z-IETD-FMK; $2 \mu \mathrm{M}$; Biovision). After 12 or 24 hours, supernatant was collected and stored at $-80^{\circ} \mathrm{C}$, and the cells fixed with neutral buffered $10 \%$ formalin solution (Sigma) for 15 mins.

\section{Murine airway epithelial cell culture}

Murine airway epithelial cells were cultured as described $(21,25)$. The cells were inoculated with PVM (MOI of 0.5 ) or vehicle, then fixed with formalin 8 hours later. In some experiments, cells were pre-treated for 30 minutes with GW80 (2 $\mu \mathrm{M}$; SYNkinase) (26) or the RIPK1 inhibitor GSK'963 (4.3 mM; GSK)(27).

\section{Mouse strains and treatments}

All studies were approved by the University of Queensland and QIMR Berghofer Animal Care and Ethics Committees. RIPK1 K45A/K45A mice (GlaxoSmithKline) and IRF7-/- mice (provided by Dr. Tadatsugu Taniguchi, University of Tokyo), were rederived and crossed to generate IRF7-/- RIPK1 ${ }^{\mathrm{K} 45 \mathrm{~A} / \mathrm{K} 45 \mathrm{~A}}$. Wild-type (WT), IRF7-/-, RIPK1 ${ }^{\mathrm{K} 45 \mathrm{~A} / \mathrm{K} 45 \mathrm{~A}}$, and IRF7-/RIPK1 $1^{\mathrm{K} 45 \mathrm{~A} / \mathrm{K} 45 \mathrm{~A}}$ mice (all C57BL/6 background) were bred in SPF animal houses at the 
University of Queensland and at QIMR Berghofer MRI. At postnatal day 7, neonatal mice were inoculated (intranasal route) with 2 plaque-forming units (PFU) of PVM (J3666 strain) in $10 \mu \mathrm{l}$ of vehicle (10\% fetal calf serum in DMEM media), as described previously (21). In some experiments, the mice were re-inoculated with 100 PFU of PVM at 42 days post infection (dpi) or given 4 weekly inoculations of $1 \mu \mathrm{g}$ of cockroach allergen extract (CRE; GREER) commencing at $42 \mathrm{dpi}$. Control mice received vehicle alone. To inhibit necroptosis, WT and IRF7-/- neonatal mice were injected (i.p. route) with Nec-1s $(6 \mathrm{mg} / \mathrm{kg}$ at 5 and $7 \mathrm{dpi}$; Biovision) (23), GSK'963 (10 mg/kg, twice daily from 5 dpi; GSK) (27), or GW806742X (GW80, $50 \mu \mathrm{g} / \mathrm{kg}$ at 7 and $9 \mathrm{dpi}$; SYNkinase). For analyses at $7 \mathrm{dpi}$, mice were treated with GW80 at 5 dpi. BALF collection occurred as described previously (28).

\section{Bronchoalveolar lavage fluid (BALF) collection, flow cytometry, cytokine analysis, immunohistochemistry and immunofluorescence, quantitative real time PCR, ALI culture and treatment.}

Details are provided in the online supplement.

\section{Statistical analysis}

Statistical analyses were performed using GraphPad Prism v.6.0 and JMP Pro (v 15.0, SAS Institute, Cary, NC). Student's t-test or the Mann-Whitney t-test were used for comparing 2 groups. When more than two groups were compared, data were analyzed using a one- or two-way ANOVA with Dunnett's or Sidak's post hoc test to compare to a control group, respectively. The specific procedure is annotated for each figure. Although our decision to use parametric analyses is based on longer term experience with the specific assays producing normal residuals (29), we examined the residuals $(\mathrm{N} \geq 16)$ from each analysis for normality using the Shapiro-Wilks test and normal quantile plots as a quality control measure. In all but one case normality was supported. In figure $2 \mathrm{C}$ there was one outlier in the RSV condition, 
which, when excluded yielded approximate normality. The results for this analysis were similar whether the outlier was excluded or not, or using robust alternatives (Kruskal-Wallis test with Dunn's post hoc test). All analyses involving the four human donor samples were also re-analysed using mixed effects models with donor as a random effect.

Differences in HMGB1 expression in nasopharygeal samples was analysed using a MannWhitney $t$ test as this assay tends to generate skewed data. We annotated statistically significant results with * or \#, $\mathrm{P}<0.05 ; * *$ or \#\#, $\mathrm{P}<0.01 ; * * *$ or \#\#\#, $\mathrm{P}<0.001$.

\section{Results}

\section{RSV infection of primary human AECs activates RIPK1 and MLKL.}

To address whether RSV infection is associated with increased levels of HMGB1, we obtained nasopharyngeal samples from young children presenting to hospital with acute respiratory infection. HMGB1 levels were significantly greater in the children infected with RSV as compared to an infection with a different respiratory virus (Fig. 1A). We then obtained human primary airway epithelial cells (hAECs) obtained from healthy children to assess mechanisms of HMGB1 release in vitro (30). RSV (MOI 1) significantly increased nuclear-to-cytoplasmic translocation of HMGB1 and extracellular HMGB1 release at $24 \mathrm{hr}$ post infection (hpi; Fig. 1B-C). This was associated with elevated release of dsDNA and LDH, and loss of plasma membrane integrity, shown by increased propidium iodide staining (PI), all indicative of cell death (PI; Fig. 1D). To explore the mode of cell death, we stained the AECs for active caspase-3 (CC3), annexin V, phosphorylated (p)RIPK1 (Ser166), and pMLKL (Ser358). The negative immunoreactivity for CC3 and Annexin V, and positive immunoreactivity for pRIPK1 and pMLKL suggested the cells were undergoing necroptosis, not apoptosis (Fig. 1E-G). These data were re-analysed using random effects models to account for possible donor effects. These analyses yielded the same conclusions and donor 
effects were not substantial or significant (data not shown).

\section{Pharmacological inhibition of RIPK1 or MLKL attenuates RSV-induced HMGB1 release.}

To assess whether necroptosis actively contributes to RSV-induced HMGB1 release at 24 hpi, we treated hAECs with Necrostatin-1s (Nec-1s) or necrosulfonamide (NSA) to inhibit RIPK1 and MLKL respectively $(31,32)$. Nec-1s treatment significantly decreased pRIPK1+ and pMLKL + cells, whereas NSA, acting downstream of pRIPK1, significantly decreased the fraction of pMLKL+ cells (Fig. 2A). The MLKL inhibitor increased CC3+ cells (Fig. 2A, bottom right panel) and annexin-V+ cells (Fig. 2B). Increased CC3 expression was ablated when both caspase- 8 and 9 were inhibited, suggesting both intrinsic and extrinsic apoptosis pathways are induced upon MLKL inhibition (Supplemental Fig. E1A). RIPK1 or MLKL inhibition significantly decreased translocation and release of HMGB1 (Fig. 2C-D), and lowered viral load (Fig. 2E, Supplemental Fig. E1B). Simultaneous inhibition of MLKL, caspase- 8 and 9 attenuated this protective effect, implicating a role for both intrinsic and extrinsic apoptosis pathways in viral clearance (Supplemental Fig. E1A). Lower viral burden after MLKL inhibition was not associated with increased type I or type III IFN expression (Supplemental Fig. E1C-E). These phenotypes were replicated in air-liquid interface (ALI) differentiated AECs (Supplemental Fig. E2). Collectively, these data suggest that necroptosis contributes to HMGB1 release and viral persistence.

\section{Pneumovirus infection induces necroptotic cell death in the airway epithelium in vivo.}

We next sought to determine whether necroptosis is pathogenic in a high-fidelity preclinical model of viral bronchiolitis. As a natural mouse pathogen, pneumonia virus of mice (PVM) can be administered at low doses, allowing for the study of host-pathogen interactions as the virus replicates $(21,28,33-36)$. We previously demonstrated that PVM infection of IRF7-/- 
mice leads to severe viral bronchiolitis, with peak viral burden occurring at $7 \mathrm{dpi}$, followed by neutrophilic inflammation, extensive epithelial sloughing, and elevated HMGB1 levels in the airway lumen at 10 and $14 \mathrm{dpi}$ (unpublished observations). As epithelial sloughing is indicative of cell death, and necroptosis has been linked to HMGB1 release $(12,37)$, we first sought to determine the temporal pattern of gene and protein expression for cell death associated caspases and kinases. At the gene level, using whole lung samples, we did not detect a significant increase in caspase-3 expression in either the WT or IRF7/- mice following PVM infection (Fig. 3A). In contrast, there was a significant increase in RIPK1, MLKL and RIPK3 gene expression in IRF7\%-- compared to WT littermates (Fig. 3A). A similar phenotype was observed regarding protein expression: pRIPK1 (Ser166) and MLKL expression was elevated in the airway epithelium at 8, 9 and 10 dpi (Fig. 3B). This was associated with elevated levels of dsDNA, LDH, and TNF $\alpha$ in the airway lumen (Supplemental Fig. E3A). MLKL expression co-localised with pRIPK1 in AECs (Fig. 3B), was typically expressed in cells with an abnormal (diffusely stained) nuclei (Supplemental Fig. E3B) and was predominantly observed at the apical surface (Supplemental Fig. E3C), consistent with other reports (38). Moreover, we observed MLKL immunoreactivity in sloughed AECs in the airway lumen, suggesting a link between necroptosis and epithelial denudation (Supplemental Fig. E3D). PVM SH gene and PVM protein levels were greater in IRF7-/- compared to WT mice, and peaked at 4 and 7 dpi respectively (Fig. 3C), the period of necroptosis onset (Fig. 3B). At both 7 and 10 dpi, the majority of MLKL+ AECs were immunoreactive for PVM (Supplemental Fig. E3E). Notably, increasing the viral inoculum to $100 \mathrm{PFU}$ in WT mice increased the fraction of pRIPK1/MLKL+ AECs to similar levels as observed in IRF7-/- mice infected with 2 PFU (Supplemental Fig. E3F), suggesting that necroptosis is influenced by viral load and can occur in immunocompetent mice. Collectively, these data suggest that Pneumovirus infection leads to necroptosis, and that this is heightened 
when innate antiviral immunity is impaired.

\section{Pharmacological inhibition of RIPK1 or MLKL decreases bronchiolitis-associated immunopathology.}

To evaluate whether necroptosis contributes to the pathogenesis of acute bronchiolitis, we treated WT and IRF7-/- mice with the RIPK1 inhibitor, Nec-1s or the MLKL inhibitor, GW80 (NSA does not inhibit murine MLKL), starting at 5 dpi (Fig. 4A). Pharmacological inhibition of RIPK1 or MLKL significantly decreased the fraction of pRIPK1 and MLKL positive AECs at 10 dpi in the IRF7-/- infected mice. Inhibition of MLKL, but not RIPK1, increased the number of CC3 expressing AECs (Fig. 4B-C), suggesting a switch in cell death modality. Treatment with either inhibitor significantly decreased viral burden (7 dpi; Fig. 4D), an effect that was not related to changes in IFN- $\alpha / \beta / \lambda$ expression (data not shown), and ameliorated neutrophilic inflammation (Fig. 4E). This was associated with a decrease in epithelial sloughing, as well as LDH, dsDNA but not TNF $\alpha$ expression (10 dpi; Fig. 4E-F, Supplemental Fig. E4A). RIPK1 or MLKL inhibition was associated with reduced cytoplasmic-HMGB1+ AECs and extracellular HMGB1 (Fig. 4G), while only MLKL inhibition decreased IL-33 levels in the airway lumen (Supplemental Fig. E4B), suggesting that the pRIPK1/MLKL necrosome regulates epithelial cell death and subsequent HMGB1 release during acute Pneumovirus infection in vivo.

\section{RIPK1 or MLKL inhibition prevents the development of type-2 inflammation.}

We next assessed the effect of Nec-1s or GW80 treatment on the induction of type-2 inflammation in PVM-infected IRF7-/- mice. Similar to our previous findings in other immunocompromised mice $(35,36)$, IL-13-producing group 2 innate lymphoid cells (ILC2s), eosinophilic inflammation, airway smooth muscle (ASM) remodeling and mucus 
hypersecretion were all elevated in IRF7-/- compared to WT mice (Fig. 5). This type-2 inflammatory response was significantly attenuated following treatment with Nec-1s or GW80 (Fig. 5). These findings were validated when mice were treated with GSK'963 (Supplemental Fig. E5), another inhibitor of RIPK1 (39), further implicating a role for necroptosis in promoting Pneumovirus-associated type-2 inflammation.

\section{RIPK1 kinase dead knock-in mice are protected from viral bronchiolitis.}

As pharmacological inhibitors can elicit off-target effects, we sought to confirm our findings using RIPK1 ${ }^{\mathrm{K} 45 \mathrm{~A} / \mathrm{K} 45 \mathrm{~A}}$ transgenic mice in which the scaffold function of RIPK1 is preserved and the kinase activity of RIPK1 is ablated (40). As expected, pRIPK1 and MLKL expression was attenuated in PVM-infected IRF7-/- RIPK1 ${ }^{\mathrm{K} 45 \mathrm{~A} / \mathrm{K} 45 \mathrm{~A}}$ Tg mice compared to IRF7-/littermate controls (Fig. 6A). Genetic inactivation of RIPK1 enzymatic activity conferred protection against severe viral bronchiolitis (high viral load, neutrophilic inflammation, AEC sloughing; Fig. 6B-C), alarmin release (HMGB1; Fig. 6D), type-2 inflammation (ILC2s, eosinophils; Fig. 6E) and airway remodeling (ASM growth, mucus hypersecretion; Fig. 6F), further suggesting that necroptosis is pathogenic in the context of RSV bronchiolitis.

\section{Pneumovirus infection induces necroptosis and HMGB1 release in differentiated mouse}

\section{AECs}

To definitively show that PVM induces the release of HMGB1 from AECs in a RIPK1 kinase dependent manner, we next cultured primary mouse AECs from WT and RIPK1 ${ }^{\mathrm{K} 45 \mathrm{~A} / \mathrm{K} 45 \mathrm{~A}} \mathrm{Tg}$ mice. As PVM does not infect undifferentiated mAECs, we differentiated the cells at airliquid interface prior to inoculation. Consistent with hAECs, Pneumovirus infection increased pRIPK1+ and MLKL+ mAECs, in the absence of a CC3+ signal (Fig. 7A), and increased dsDNA in the basal media at 24 hpi (Fig. 7B). In the absence of RIPK1 kinase activity, pRIPK1+ and MLKL+ cells were significantly decreased (Fig.7C), as was translocation and 
release of HMGB1 (Fig.7D). Similarly, treatment of WT mAECs with Nec-1s decreased HMGB1 translocation, and both Nec-1s or GW80 decreased HMGB1 release (Fig.7E). Consistent with the in vivo findings, CC3 was elevated in PVM-infected mAECs treated with the MLKL, but not the RIPK1 inhibitor (Fig. 7F).

\section{Inhibition of pRIPK1or MLKL during severe bronchiolitis prevents progression to later} asthma.

Severe or frequent lower respiratory infections are an independent risk factor for asthma (24). This epidemiology is captured in our preclinical model as a secondary insult promotes experimental asthma (35) Therefore, we hypothesised that inhibition of Pneumovirusassociated necroptosis in early life would prevent the later development of virus- or allergeninduced asthma. WT and IRF7-/- mice were infected with PVM in early life and treated with Nec-1s or GW80 in infancy, then 6 weeks later, challenged with either PVM or exposed to cockroach extract (once/week for 4 weeks) to induce experimental asthma (Fig. 8A). Pharmacological inhibition of RIPK1 or MLKL in neonates decreased ASM remodelling, mucus hypersecretion, and eosinophilic inflammation in the predisposed IRF7/-- mice (Fig. 8B-E).

\section{Discussion}

New therapies are needed to reduce the significant mortality and morbidity associated with RSV bronchiolitis (1). Here we show that infection with human RSV or mouse PVM induces necroptosis in AECs using both in vivo and in vitro model systems, and that this contributes to disease pathology and pathogenesis. Specifically, we show that inhibition of pRIPK1 kinase activity or MLKL ablates RSV/PVM associated necroptosis, attenuating the release of the pro-inflammatory alarmin HMGB1, and downstream sequelae. In addition to improving viral control and ameliorating viral bronchiolitis associated immunopathology, inhibition of 
necroptosis in infancy protected against the later development of viral and allergic experimental asthma.

A hallmark of severe viral bronchiolitis is the loss of airway epithelial integrity, leading to epithelial cell sloughing and formation of Creola bodies in the airway lumen (41). However, the mode of cell death has remained elusive. Using cultured human AECs, we and others have shown that RSV infection does not increase caspase-3/7 or caspase- 9 activity, markers of apoptotic death $(42,43)$. This response may reflect the ability of RSV, via non-structural protein-1 and 2 and other molecules, to actively inhibit apoptosis (43-45). Here we confirm that RSV infection fails to induce apoptosis, and show for the first time in human primary AECs that RSV induces RIPK1 activation (monitored by auto-phosphorylation on Ser166) and MLKL-dependent loss of cell viability, indicative of necroptosis. Inhibition of pRIPK1 kinase activity or MLKL decreased cytoplasmic translocation and release of HMGB1, and also decreased viral burden, suggesting that therapies which ablate epithelial necroptosis will exhibit dual anti-viral and anti-inflammatory activity.

To explore the contribution of necroptosis in vivo, we utilised a neonatal model of severe bronchiolitis that employs low dose viral infection in a genetically susceptible host (to simulate the gene-environment interactions that underpin disease) (35). Notably, epithelial sloughing, a hallmark feature of bronchiolitis, is absent in mice following inoculation with hRSV, even at supraphysiological doses. This likely reflects the fact that Pneumoviruses are host-specific $(46,47)$. By performing temporal studies, we show in PVM-infected neonatal IRF7-/- mice that necroptosis, (i) is the primary model of airway epithelial cell death during bronchiolitis, (ii) is initiated soon after peak viral replication, and (iii) precedes the development of airway remodeling and type-2 inflammation. Pharmacologic or genetic ablation of necroptosis decreased AEC sloughing and attenuated the pro-inflammatory 
neutrophilic response. This prevented the development of type-2 inflammation and ASM remodeling in infancy and later development of experimental asthma. This was particularly apparent in mice treated with the MLKL inhibitor, which had a greater impact on eosinophils, compared to RIPK1 inhibition, suggesting either RIPK1 conveys some small protective functions or that MLKL is involved in cell death-independent pathways that promote type-2 inflammation. The impetus for this study stemmed from our unpublished observations demonstrating that HMGB1 is highly pathogenic in the context of bronchiolitis and reports in the literature linking necroptosis to HMGB1 release (12, 37). We show that HMGB1 levels are elevated in nasopharyngeal samples of RSV infected children, and that the beneficial effects of inhibiting necroptosis (in vivo in mice and in vitro cultured AECs) are associated with a marked decrease in HMGB1 levels. Thus, our findings suggest that inhibiting HMGB1, through monoclonal antibody-mediated neutralisation or inhibition of necroptosis, will reduce the high morbidity, and potentially mortality, of severe RSV bronchiolitis. By ablating the onset of type- 2 inflammation and ASM remodeling, necroptosis inhibitors may serve as primary preventatives for asthma in predisposed individuals.

In both in vitro and in vivo models, genetic or pharmacologic inhibition of RIPK1 kinase activity and MLKL decreased viral load. This was unexpected in the in vivo model because the increase in pRIPK1/MLKL at 7 dpi was not statistically significant. However, it is apparent from the time course studies that the upregulation and phosphorylation of necroptosis-associated proteins is initiated between 4 and 7 dpi, followed by a sharp increase at 8-10 dpi, inferring a feed-forward loop. In other investigations of necroptosis-associated kinases, RIPK3 was shown to limit the propagation of herpes simplex virus, influenza virus A and vaccinia virus $(17,48,49)$, although notably this phenotype was not observed with influenza H7H9 infection (50). RIPK3 can contribute to both apoptosis and necroptosis, and is involved in pro-inflammatory cytokine production, complicating interpretations. As such, 
even though its expression was increased in PVM-infected mice, we did not seek to assess the role of RIPK3 in the present study. Unlike RIPK3 deficiency, genetic deletion of MLKL did not affect influenza virus A replication or clearance (48). In summary, the consequence of necroptosis on viral pathogenesis appears to be context and virus-dependent; the latter potentially relating to the ability of the virus to preferentially inhibit or induce apoptosis and/or necroptosis.

The mechanism by which inhibition of necroptosis lowered Pneumovirus load remains elusive. In both the in vivo and in vitro models, inhibition of necroptosis did not lead to an increase in the expression of type I or type III IFNs. However, inhibition of MLKL led to a significant increase in the number of active caspase- 3 immunoreactive epithelial cells, despite two different MLKL inhibitors being used. This highly reproducible phenotype was not apparent after RIPK1 inhibition, suggesting that the inhibition of MLKL initiates a RIPK1dependent apoptotic pathway. The propensity for necroptosis over apoptosis following Pneumovirus infection suggests that the virus subverts apoptosis, which is well established; our findings suggest that blocking necroptosis either overcomes this subversion or initiates a different pathway to apoptosis that is not inhibited by the virus. Further studies are needed to reveal these molecular processes; however, we were able to implicate both intrinsic and extrinsic apoptosis pathways as dual inhibition of caspase- 8 and -9 prevented processing of caspase-3 and the fall in viral load induced via MLKL inhibition.

Typically, the induction of necroptosis is achieved by sensitising cells via the use of a chemical agent, and consequently such studies are less physiologically relevant. A strength of this study is that RSV/PVM naturally induced necroptosis without the use of an apoptosis inhibitor, likely due to the anti-caspase activity of the virus or ablation of a necroptosis repressor. Multiple pro-inflammatory pathways can induce necroptosis upon viral infection, 
including TLR, IFN or TNF receptor activation $(13,14,18)$. A limitation of the current study is that we did not explore this specifically, however the elevated viral load, in the absence of increased IFNs or TNF at 7 or $8 \mathrm{dpi}$, implicates a virus-sensing pattern recognition receptor.

In summary, we demonstrate that in their host-specific setting, Pneumoviruses induce necroptosis in AECs, leading to release of HMGB1. Inhibition of RIPK1 kinase activity or MLKL ameliorates the severity of bronchiolitis by decreasing viral load and immunopathology, which in turn prevents the development of type-2 inflammation and associated ASM remodelling. Consequently, susceptibility to later asthma is lowered. Our findings implicate necroptosis in the pathogenies of bronchiolitis and suggest that therapeutic targeting of its effector kinases would ameliorate bronchiolitis severity and potentially act as an asthma preventative in a subpopulation of individuals whose aetiology is linked to earlylife viral infections. Further work is required to identify safe and effective ways to target this important pathway, a critical step in developing future RSV therapies. 


\section{References:}

1. Nair H, Simoes EA, Rudan I, Gessner BD, Azziz-Baumgartner E, Zhang JS, Feikin DR, Mackenzie GA, Moisi JC, Roca A, Baggett HC, Zaman SM, Singleton RJ, Lucero MG, Chandran A, Gentile A, Cohen C, Krishnan A, Bhutta ZA, Arguedas A, Clara AW, Andrade AL, Ope M, Ruvinsky RO, Hortal M, McCracken JP, Madhi SA, Bruce N, Qazi SA, Morris SS, El Arifeen S, Weber MW, Scott JA, Brooks WA, Breiman RF, Campbell H, Severe Acute Lower Respiratory Infections Working G. Global and regional burden of hospital admissions for severe acute lower respiratory infections in young children in 2010: a systematic analysis. Lancet 2013; 381: 1380-1390.

2. Feldman AS, He Y, Moore ML, Hershenson MB, Hartert TV. Toward primary prevention of asthma. Reviewing the evidence for early-life respiratory viral infections as modifiable risk factors to prevent childhood asthma. American journal of respiratory and critical care medicine 2015; 191: 34-44.

3. Singh AM, Moore PE, Gern JE, Lemanske RF, Jr., Hartert TV. Bronchiolitis to asthma: a review and call for studies of gene-virus interactions in asthma causation. American journal of respiratory and critical care medicine 2007; 175: 108-119.

4. Toivonen L, Forsstrom V, Waris M, Peltola V. Acute respiratory infections in early childhood and risk of asthma at age 7 years. The Journal of allergy and clinical immunology 2018.

5. Everard ML, Swarbrick A, Wrightham M, McIntyre J, Dunkley C, James PD, Sewell HF, Milner AD. Analysis of cells obtained by bronchial lavage of infants with respiratory syncytial virus infection. Arch Dis Child 1994; 71: 428-432.

6. Johnson JE, Gonzales RA, Olson SJ, Wright PF, Graham BS. The histopathology of fatal 
untreated human respiratory syncytial virus infection. Modern pathology : an official journal of the United States and Canadian Academy of Pathology, Inc 2007; 20: 108119.

7. Aherne W, Bird T, Court SD, Gardner PS, McQuillin J. Pathological changes in virus infections of the lower respiratory tract in children. Journal of clinical pathology 1970; 23: 7-18.

8. Stetson DB, Medzhitov R. Type I interferons in host defense. Immunity 2006; 25: 373381.

9. De Cosmi V, Mehta NM, Boccazzi A, Milani GP, Esposito S, Bedogni G, Agostoni C. Nutritional status, metabolic state and nutrient intake in children with bronchiolitis. Int J Food Sci Nutr 2017; 68: 378-383.

10. Janssen R, Bont L, Siezen Christine LE, Hodemaekers Hennie M, Ermers Marieke J, Doornbos G, Slot Ruben vt, Wijmenga C, Goeman Jelle J, Kimpen Jan LL, van Houwelingen Hans C, Kimman Tjeerd G, Hoebee B. Genetic Susceptibility to Respiratory Syncytial Virus Bronchiolitis Is Predominantly Associated with Innate Immune Genes. The Journal of Infectious Diseases 2007; 196: 826-834.

11. Siezen CL, Bont L, Hodemaekers HM, Ermers MJ, Doornbos G, Van't Slot R, Wijmenga C, Houwelingen HC, Kimpen JL, Kimman TG, Hoebee B, Janssen R. Genetic susceptibility to respiratory syncytial virus bronchiolitis in preterm children is associated with airway remodeling genes and innate immune genes. Pediatr Infect Dis $J 2009$; 28: 333-335.

12. Qing DY, Conegliano D, Shashaty MG, Seo J, Reilly JP, Worthen GS, Huh D, Meyer NJ, Mangalmurti NS. Red blood cells induce necroptosis of lung endothelial cells and 
increase susceptibility to lung inflammation. American journal of respiratory and critical care medicine 2014; 190: 1243-1254.

13. Robinson N, McComb S, Mulligan R, Dudani R, Krishnan L, Sad S. Type I interferon induces necroptosis in macrophages during infection with Salmonella enterica serovar Typhimurium. Nature immunology 2012; 13: 954-962.

14. Vanlangenakker N, Bertrand MJ, Bogaert P, Vandenabeele P, Vanden Berghe T. TNFinduced necroptosis in L929 cells is tightly regulated by multiple TNFR1 complex and II members. Cell death \& disease 2011; 2: e230.

15. Bell CW, Jiang W, Reich CF, 3rd, Pisetsky DS. The extracellular release of HMGB1 during apoptotic cell death. American journal of physiology Cell physiology 2006; 291: C1318-1325.

16. Vandenabeele P, Galluzzi L, Vanden Berghe T, Kroemer G. Molecular mechanisms of necroptosis: an ordered cellular explosion. Nature reviews Molecular cell biology $2010 ; 11: 700-714$

17. Cho YS, Challa S, Moquin D, Genga R, Ray TD, Guildford M, Chan FK. Phosphorylation-driven assembly of the RIP1-RIP3 complex regulates programmed necrosis and virus-induced inflammation. Cell 2009; 137: 1112-1123.

18. Takemura R, Takaki H, Okada S, Shime H, Akazawa T, Oshiumi H, Matsumoto M, Teshima T, Seya T. PolyI:C-Induced, TLR3/RIP3-Dependent Necroptosis Backs Up Immune Effector-Mediated Tumor Elimination In Vivo. Cancer immunology research 2015; 3: 902-914.

19. Gaba A, Xu F, Lu Y, Park HS, Liu G, Zhou Y. The Ns1 Protein of Influenza a Virus 
Participates in Necroptosis by Interacting with Mlkl and Increasing Its

Oligomerization and Membrane Translocation. J Virol 2018.

20. Spann KM, Baturcam E, Schagen J, Jones C, Straub CP, Preston FM, Chen L, Phipps S, Sly PD, Fantino E. Viral and host factors determine innate immune responses in airway epithelial cells from children with wheeze and atopy. Thorax 2014; 69: 918925.

21. Werder RB, Lynch JP, Simpson JC, Zhang V, Hodge NH, Poh M, Forbes-Blom E, Kulis C, Smythe ML, Upham JW, Spann K, Everard ML, Phipps S. PGD2/DP2 receptor activation promotes severe viral bronchiolitis by suppressing IFN-lambda production. Sci Transl Med 2018; 10.

22. Schagen J, Sly PD, Fantino E. Characterizing well-differentiated culture of primary human nasal epithelial cells for use in wound healing assays. Laboratory Investigation 2018; 98: 1478-1486.

23. Takahashi N, Duprez L, Grootjans S, Cauwels A, Nerinckx W, DuHadaway JB, Goossens V, Roelandt R, Van Hauwermeiren F, Libert C, Declercq W, Callewaert N, Prendergast GC, Degterev A, Yuan J, Vandenabeele P. Necrostatin-1 analogues: critical issues on the specificity, activity and in vivo use in experimental disease models. Cell death \& disease 2012; 3: e437.

24. Kitur K, Parker D, Nieto P, Ahn DS, Cohen TS, Chung S, Wachtel S, Bueno S, Prince A. Toxin-Induced Necroptosis Is a Major Mechanism of Staphylococcus aureus Lung Damage. PLoS pathogens 2015; 11: e1004820.

25. Rock JR, Onaitis MW, Rawlins EL, Lu Y, Clark CP, Xue Y, Randell SH, Hogan BL. Basal cells as stem cells of the mouse trachea and human airway epithelium. 
Proceedings of the National Academy of Sciences of the United States of America 2009; 106: 12771-12775.

26. Hildebrand JM, Tanzer MC, Lucet IS, Young SN, Spall SK, Sharma P, Pierotti C, Garnier JM, Dobson RC, Webb AI, Tripaydonis A, Babon JJ, Mulcair MD, Scanlon MJ, Alexander WS, Wilks AF, Czabotar PE, Lessene G, Murphy JM, Silke J. Activation of the pseudokinase MLKL unleashes the four-helix bundle domain to induce membrane localization and necroptotic cell death. Proc Natl Acad Sci U S A 2014; 111: 15072-15077.

27. Berger SB, Harris P, Nagilla R, Kasparcova V, Hoffman S, Swift B, Dare L, Schaeffer M, Capriotti C, Ouellette M, King BW, Wisnoski D, Cox J, Reilly M, Marquis RW, Bertin J, Gough PJ. Characterization of GSK'963: a structurally distinct, potent and selective inhibitor of RIP1 kinase. Cell Death Discov 2015; 1: 15009.

28. Lynch JP, Werder RB, Simpson J, Loh Z, Zhang V, Haque A, Spann K, Sly PD, Mazzone SB, Upham JW, Phipps S. Aeroallergen-induced IL-33 predisposes to respiratory virus-induced asthma by dampening antiviral immunity. The Journal of allergy and clinical immunology 2016.

29. Rochon J, Gondan M, Kieser M. To test or not to test: Preliminary assessment of normality when comparing two independent samples. BMC Medical Research Methodology 2012; 12: 81.

30. Hosakote YM, Brasier AR, Casola A, Garofalo RP, Kurosky A. RSV Infection Triggers Epithelial HMGB1 Release as a Damage-Associated Molecular Pattern Promoting a Monocytic Inflammatory Response. J Virol 2016.

31. Arshad MI, Piquet-Pellorce C, Filliol A, L'Helgoualc'h A, Lucas-Clerc C, Jouan- 
Lanhouet S, Dimanche-Boitrel MT, Samson M. The chemical inhibitors of cellular death, PJ34 and Necrostatin-1, down-regulate IL-33 expression in liver. Journal of molecular medicine 2015; 93: 867-878.

32. Petrie EJ, Hildebrand JM, Murphy JM. Insane in the membrane: a structural perspective of MLKL function in necroptosis. Immunology and cell biology 2016.

33. Simpson J, Lynch JP, Loh Z, Zhang V, Werder RB, Spann K, Phipps S. The Absence of Interferon- $\beta$ Promotor Stimulator-1 (IPS-1) Predisposes to Bronchiolitis and Asthmalike Pathology in Response to Pneumoviral Infection in Mice. Scientific Reports 2017; 7.

34. Kaiko GE, Phipps S, Angkasekwinai P, Dong C, Foster PS. NK cell deficiency predisposes to viral-induced Th2-type allergic inflammation via epithelial-derived IL25. J Immunol 2010; 185: 4681-4690.

35. Lynch JP, Werder RB, Loh Z, Sikder MAA, Curren B, Zhang V, Rogers MJ, Lane K, Simpson J, Mazzone SB, Spann K, Hayball J, Diener K, Everard ML, Blyth CC, Forstner C, Dennis PG, Murtaza N, Morrison M, P OC, Zhang P, Haque A, Hill GR, Sly PD, Upham JW, Phipps S. Plasmacytoid dendritic cells protect from viral bronchiolitis and asthma through semaphorin 4a-mediated T reg expansion. $J$ Exp Med 2018; 215: 537-557.

36. Kaiko GE, Loh Z, Spann K, Lynch JP, Lalwani A, Zheng Z, Davidson S, Uematsu S, Akira S, Hayball J, Diener KR, Baines KJ, Simpson JL, Foster PS, Phipps S. Toll-like receptor 7 gene deficiency and early-life Pneumovirus infection interact to predispose toward the development of asthma-like pathology in mice. The Journal of allergy and clinical immunology 2013; 131: 1331-1339 e1310. 
37. Mizumura K, Cloonan SM, Nakahira K, Bhashyam AR, Cervo M, Kitada T, Glass K, Owen CA, Mahmood A, Washko GR, Hashimoto S, Ryter SW, Choi AM. Mitophagy-dependent necroptosis contributes to the pathogenesis of COPD. The Journal of clinical investigation 2014; 124: 3987-4003.

38. Cai Z, Jitkaew S, Zhao J, Chiang HC, Choksi S, Liu J, Ward Y, Wu LG, Liu ZG. Plasma membrane translocation of trimerized MLKL protein is required for TNF-induced necroptosis. Nature cell biology 2014; 16: 55-65.

39. Weng D, Marty-Roix R, Ganesan S, Proulx MK, Vladimer GI, Kaiser WJ, Mocarski ES, Pouliot K, Chan FK, Kelliher MA, Harris PA, Bertin J, Gough PJ, Shayakhmetov DM, Goguen JD, Fitzgerald KA, Silverman N, Lien E. Caspase-8 and RIP kinases regulate bacteria-induced innate immune responses and cell death. Proceedings of the National Academy of Sciences of the United States of America 2014; 111: 7391-7396.

40. Berger SB, Kasparcova V, Hoffman S, Swift B, Dare L, Schaeffer M, Capriotti C, Cook M, Finger J, Hughes-Earle A, Harris PA, Kaiser WJ, Mocarski ES, Bertin J, Gough PJ. Cutting Edge: RIP1 kinase activity is dispensable for normal development but is a key regulator of inflammation in SHARPIN-deficient mice. Journal of immunology 2014; 192: 5476-5480.

41. Visscher DW, Myers JL. Bronchiolitis: the pathologist's perspective. Proceedings of the American Thoracic Society 2006; 3: 41-47.

42. Baturcam E, Snape N, Yeo TH, Schagen J, Thomas E, Logan J, Galbraith S, Collinson N, Phipps S, Fantino E, Sly PD, Spann KM. Human Metapneumovirus Impairs Apoptosis of Nasal Epithelial Cells in Asthma via HSP70. Journal of innate immunity 2016. 
43. Thomas KW, Monick MM, Staber JM, Yarovinsky T, Carter AB, Hunninghake GW. Respiratory syncytial virus inhibits apoptosis and induces NF-kappa B activity through a phosphatidylinositol 3-kinase-dependent pathway. The Journal of biological chemistry 2002; 277: 492-501.

44. Bitko V, Shulyayeva O, Mazumder B, Musiyenko A, Ramaswamy M, Look DC, Barik S. Nonstructural proteins of respiratory syncytial virus suppress premature apoptosis by an NF-kappaB-dependent, interferon-independent mechanism and facilitate virus growth. J Virol 2007; 81: 1786-1795.

45. Groskreutz DJ, Monick MM, Yarovinsky TO, Powers LS, Quelle DE, Varga SM, Look DC, Hunninghake GW. Respiratory syncytial virus decreases p53 protein to prolong survival of airway epithelial cells. Journal of immunology 2007; 179: 2741-2747.

46. Bem RA, Domachowske JB, Rosenberg HF. Animal models of human respiratory syncytial virus disease. Am J Physiol Lung Cell Mol Physiol 2011; 301: L148-156.

47. Schmidt ME, Oomens AGP, Varga SM. Single-cycle respiratory syncytial virus infection induces robust adaptive immune responses and reduces disease severity in mice. The Journal of Immunology 2018; 200: 60.62-60.62.

48. Nogusa S, Thapa Roshan J, Dillon Christopher P, Liedmann S, Oguin Thomas H, Ingram Justin P, Rodriguez Diego A, Kosoff R, Sharma S, Sturm O, Verbist K, Gough Peter J, Bertin J, Hartmann Boris M, Sealfon Stuart C, Kaiser William J, Mocarski Edward S, López Carolina B, Thomas Paul G, Oberst A, Green Douglas R, Balachandran S. RIPK3 Activates Parallel Pathways of MLKL-Driven Necroptosis and FADD Mediated Apoptosis to Protect against Influenza A Virus. Cell host \& microbe 2016.

49. Huang Z, Wu SQ, Liang Y, Zhou X, Chen W, Li L, Wu J, Zhuang Q, Chen C, Li J, 
Zhong CQ, Xia W, Zhou R, Zheng C, Han J. RIP1/RIP3 Binding to HSV-1 ICP6 Initiates Necroptosis to Restrict Virus Propagation in Mice. Cell host \& microbe 2015; 17: 229-242.

50. Xu YL, Tang HL, Peng HR, Zhao P, Qi ZT, Wang W. RIP3 deficiency ameliorates inflammatory response in mice infected with influenza H7N9 virus infection. Oncotarget 2017. 


\section{Figure legends:}

\section{Figure 1: RSV infection of primary human AECs activates RIPK1 and MLKL.}

(A) HMGB1 levels assessed in nasopharyngeal samples obtained from young children presenting with acute respiratory infection with RSV or other respiratory viruses.

(B-G) Submerged primary human AECs were infected with RSV (MOI of 1), and HMGB1 expression and various analyses of cell death examined at 12 and 24 hours.

(B) Representative micrographs (x400 magnification) of HMGB1 (green) in AECs. Quantification of cyto-HMGB1.

(C) Protein expression of HMGB1 in supernatant.

(D) Expression of dsDNA and LDH in supernatant. Quantification of PI positive AECs.

(E) Quantification of cleaved caspase-3 and annexin V positive AECs.

(F) Representative micrographs (x400 magnification) of pRIPK1 (red) in AECs. Quantification of pRIPK1 positive AECs.

(G) Representative micrographs (x400 magnification) of pMLKL (red) in AECs. Quantification of pMLKL positive AECs.

Data are representative of $n=2$ experiments with four donors in each group and are presented as box-and-whisker plots showing quartiles (boxes) and range (whiskers). Data were analyzed using Mann-Whitney T test (A) or two-way ANOVA with Sidak's post hoc test. *, $\mathrm{P}<0.05 ; * *, \mathrm{P}<0.01 ; * * *, \mathrm{P}<0.001$ denote significance between infected and uninfected hAECs at each time point. 


\section{Figure 2: Pharmacological inhibition of RIPK1 or MLKL attenuates RSV-induced}

\section{HMGB1 release.}

Submerged hAECs were pre-treated with a RIPK1 inhibitor (Nec-1s) or MLKL inhibitor (NSA) prior to infection with RSV (MOI of 1).

(A) Representative micrographs (x400 magnification) of pRIPK1 (red), and pMLKL (red) and cleaved caspase-3 (green), and quantification of pRIPK1, pMLKL and cleaved caspase-3 (CC3) positive AECs.

(B) Quantification of annexin V positive AECs.

(C) Quantification of cyto-HMGB1 positive AECs.

(D) HMGB1 protein expression in supernatant.

(E) Quantification of RSV positive AECs.

Data are representative of $n=2$ experiments with four donors in each group and are presented as box-and-whisker plots showing quartiles (boxes) and range (whiskers). Data were analyzed by one-way ANOVA with Dunnett's post hoc test. *, $\mathrm{P}<0.05$; **, $\mathrm{P}<0.01$ and ***, $\mathrm{P}<0.001$ are compared to uninfected hAECs and \#, $\mathrm{P}<0.05$; \#\#, $\mathrm{P}<0.01$; \#\#\#, $\mathrm{P}<0.001$ are compared to RSV-infected hAECs.

Figure 3: In vivo Pneumovirus infection induces necroptotic cell death in the airway epithelium.

Neonatal WT and IRF7-/- mice were infected with PVM (2 pfu) and cell death-related genes/proteins and viral load assessed over time.

(A) Lung gene expression of caspase-3, Ripk1, Mlkl and Ripk3. 
(B) Representative micrographs (x400 magnification) of cleaved caspase-3 (green), pRIPK1 (red) and pMLKL (yellow). Quantification of pRIPK1, pMLKL and cleaved caspase-3 (CC3) in AECs.

(C) Lung gene expression of PVM SH gene. Representative micrographs (x400 magnification) of PVM (green) and quantification of PVM positive AECs.

Data are representative of $\mathrm{n}=2$ experiments with four to six neonates in each group and are presented as mean \pm S.E.M.. Data were analyzed by two-way ANOVA with Sidak's post hoc test. *, $\mathrm{P}<0.05 ; * *, \mathrm{P}<0.01 ; * * *, \mathrm{P}<0.001$ are compared to $\mathrm{PVM}$ infected $\mathrm{WT}$ at each time point.

Figure 4: Inhibition of RIPK1 or pMLKL reduces alarmin release and bronchiolitis in IRF7 $^{-/-}$mice during acute viral infection.

Neonatal WT and IRF7/-- mice were infected with PVM (2 pfu) at 7 days of age. Mice were treated with either a RIPK1 inhibitor (Nec-1s) or MLKL inhibitor (GW80). Alarmin release and bronchiolitis-associated pathologies were assessed at 7 and $10 \mathrm{dpi}$.

(A) Study design.

(B) Quantification of pRIPK1 and MLKL positive AECs.

(C) Quantification of cleaved caspase-3 (CC3) positive AECs.

(D) Quantification of PVM positive AECs.

(E) AEC sloughing normalised to basement membrane length. Neutrophils in BALF.

(F) LDH and dsDNA in BALF.

(G) Quantification of cyto-HMGB1 and HMGB1 protein expression in BALF. 
Data are representative of $n=2$ experiments with four to six neonates in each group and are presented as box-and-whisker plots showing quartiles (boxes) and range (whiskers). Data were analyzed by two-way ANOVA with Sidak's post hoc test. *, $\mathrm{P}<0.05$; **, $\mathrm{P}<0.01$ and ***, $\mathrm{P}<0.001$ are compared to untreated (diluent) WT or IRF7 ${ }^{-/-}$infected mice. \#, $\mathrm{P}<0.05$; \#\#, $\mathrm{P}<0.01$ and \#\#\#, $\mathrm{P}<0.001$ are compared to Nec-1s treated WT or IRF7-/- infected mice.

\section{Figure 5: Inhibition of RIPK1 or MLKL prevents the development of type-2 inflammation.}

Neonatal WT and IRF7--- mice were infected with PVM (2 pfu) at 7 days of age. Mice were treated with either a RIPK1 inhibitor (Nec-1s) or MLKL inhibitor (GW80) and markers of type-2 inflammation assessed at $10 \mathrm{dpi}$.

(A) Total ILC2s in lung. The number of IL-13+ ILC2s in the lung were quantified in 4C13R/WT and 4C13R/IRF7-/- infected mice.

(B) Eosinophils in BALF.

(C) Representative micrograph (x100 magnification) and quantification of ASM.

(D) Representative micrograph (x100 magnification) and quantification of Muc5ac positive AECs.

Data are representative of $\mathrm{n}=2$ experiments with four to six neonates in each group and are presented as box-and-whisker plots showing quartiles (boxes) and range (whiskers). Data were analyzed by two-way ANOVA with Sidak's post hoc test. * ${ }^{*} \mathrm{P}<0.05 ; * *, \mathrm{P}<0.01 ; * * *$, $\mathrm{P}<0.001$ are compared to untreated (diluent) WT or IRF7 ${ }^{-/-}$or $4 \mathrm{C} 13 \mathrm{R} / \mathrm{WT}$ or $4 \mathrm{C} 13 \mathrm{R} / \mathrm{IRF} 7^{-/-}$ infected mice. \#, $\mathrm{P}<0.05$; \#\#, $\mathrm{P}<0.01$ and \#\#\#, $\mathrm{P}<0.001$ are compared to Nec- 1 s treated WT or IRF7-/- infected mice. 


\section{Figure 6: RIPK1 kinase dead knock-in mice are protected from viral bronchiolitis.}

Neonatal WT, RIPK1 ${ }^{\mathrm{K} 45 \mathrm{~A} / \mathrm{K} 45 \mathrm{~A}}$, IRF7-/- and IRF7-/- RIPK $1^{\mathrm{K} 45 \mathrm{~A} / \mathrm{K} 45 \mathrm{~A}}$ were infected with PVM (2 pfu) at 7 days of age. Alarmin release and bronchiolitis-associated pathologies were assessed at 7 and 10 dpi.

(A) Quantification of pRIPK1, MLKL and cleaved caspase-3 (CC3) positive AECs.

(B) Quantification of PVM.

(C) Neutrophils in BALF and quantification of AEC sloughing.

(D) Quantification of cytoplasmic HMGB1 and HMGB1 expression in BALF.

(E) ILC2s in lung and eosinophils in BALF.

(F) Quantification of ASM area and Muc5ac positive AECs.

Data are representative of $\mathrm{n}=2$ experiments with four to six neonates in each group and are presented as box-and-whisker plots showing quartiles (boxes) and range (whiskers). Data were analyzed by one-way with Dunnett's post hoc test. *, $\mathrm{P}<0.05 ; * *, \mathrm{P}<0.01$; ***, $\mathrm{P}$ $<0.001$ are compared to IRF7-/- infected mice.

Figure 7: Murine Pneumovirus infection induces necroptosis and HMGB1 release in differentiated mouse AECs.

Mouse AECs were differentiated at air-liquid interface. Cells were infected with PVM and expression of HMGB1 and necroptosis proteins were assessed at 24 hours post infection.

(A) Representative images (x400 magnification) of cleaved caspase-3 (green), pRIPK1 (red) and MLKL (yellow). Quantification of cleaved caspase-3 (CC3), pRIPK1 and MLKL positive AECs. 
(B) dsDNA expression in basal media.

(C) Quantification of pRIPK1 and MLKL positive AECs.

(D) Quantification of cyto-HMGB1 positive AECs. HMGB1 protein expression in basal media.

(E) Quantification of cyto-HMGB1 positive AECs. HMGB1 protein expression in basal media.

(F) Quantification of cleaved caspase-3 positive AECs.

Data are representative of $n=2$ experiments with four to seven neonates in each group and are presented as box-and-whisker plots showing quartiles (boxes) and range (whiskers). Data were analyzed using Student's t test (A-B) or two-way ANOVA with Sidak's post hoc test (C-D) or one-way ANOVA with Dunnett post hoc test (E-F). ${ }^{*}, \mathrm{P}<0.05$; **, $\mathrm{P}<0.01$; ***, $\mathrm{P}$ $<0.001$ are compared to uninfected mAECs $(\mathrm{A}, \mathrm{B}, \mathrm{E}, \mathrm{F})$ or PVM-infected RIPK $1^{\mathrm{K} 45 \mathrm{~A} / \mathrm{K} 45 \mathrm{~A}}$ mAECs (C-D). \#, $\mathrm{P}<0.05$ and \#\#, $\mathrm{P}<0.01$ compared to PVM-infected WT mAECs.

Figure 8: Inhibition of pRIPK1 or MLKL during severe bronchiolitis prevents progression to later asthma.

Neonatal WT and IRF7-/- mice were infected with PVM (2 pfu), treated with the RIPK1 (Nec-1s) or MLKL inhibitor (GW80), then challenged with PVM (left hand panel in C-E) or cockroach allergen (right hand panel in C-E) in later life.

(A) Study design.

(B) Representative micrograph of Muc5ac (red; x200 magnification) and ASM staining (red; x100 magnification) in PVM/PVM infected IRF7-/- mice. 
(C) Quantification of Muc5ac positive cells.

(D) Quantification of ASM area.

(E) Eosinophils in BALF.

Data are representative of $n=2$ experiments with three to six neonates in each group and are presented as box-and-whisker plots showing quartiles (boxes) and range (whiskers). Data were analyzed using two-way ANOVA with Sidak's post hoc test. *, $\mathrm{P}<0.05$; **, $\mathrm{P}<0.01$; $* * *, \mathrm{P}<0.001$ are compared to untreated (diluent) WT or IRF7 ${ }^{-/-}$infected mice. \#\#, $\mathrm{P}<0.01$ is compared to Nec-1s treated WT or IRF7-/- infected mice. 
Figure 1
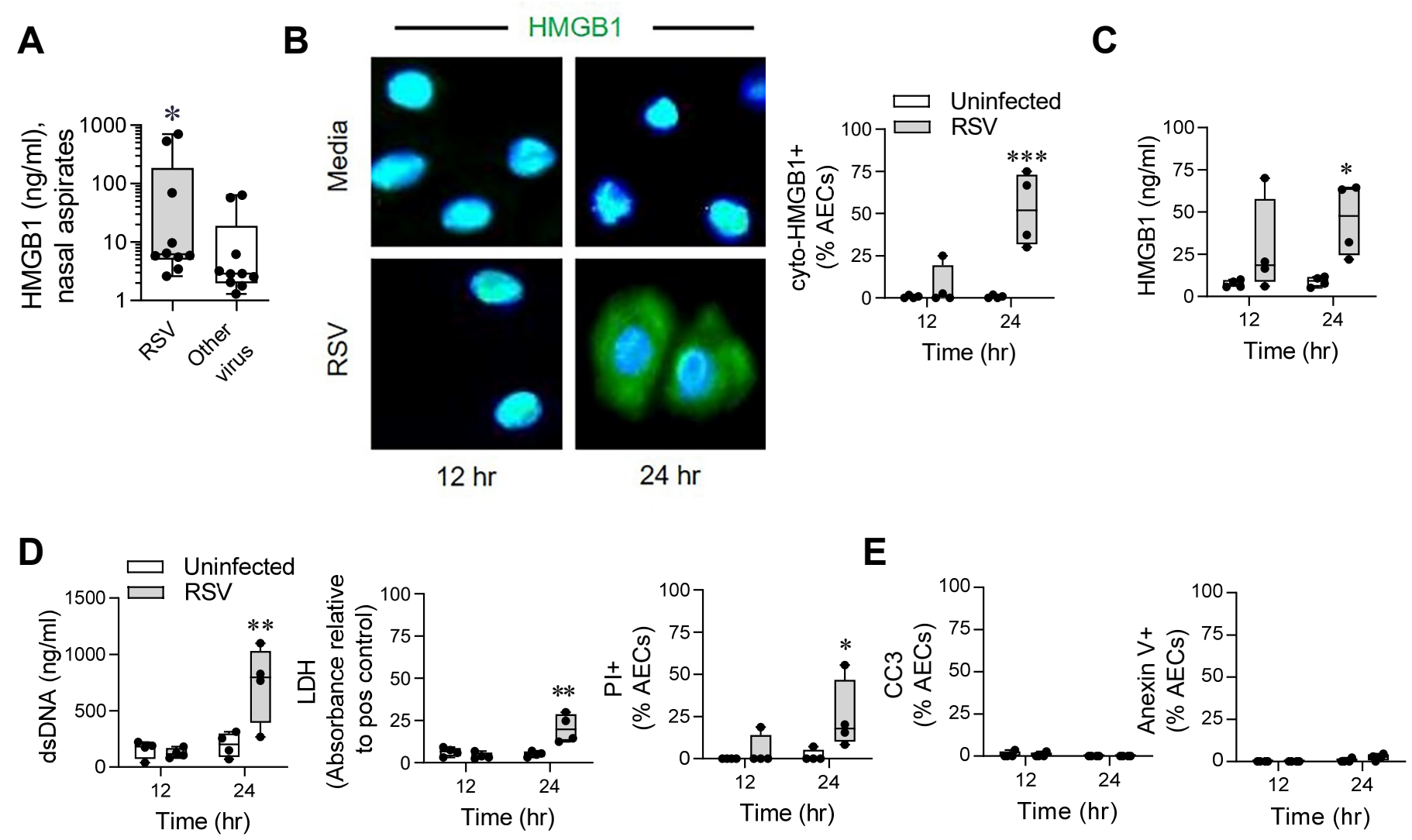

\section{$\mathbf{F}$}
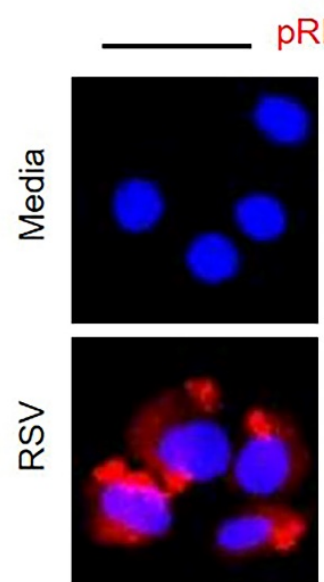

$12 \mathrm{hr}$
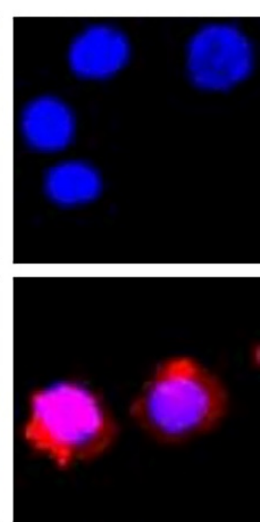

$24 \mathrm{hr}$

G
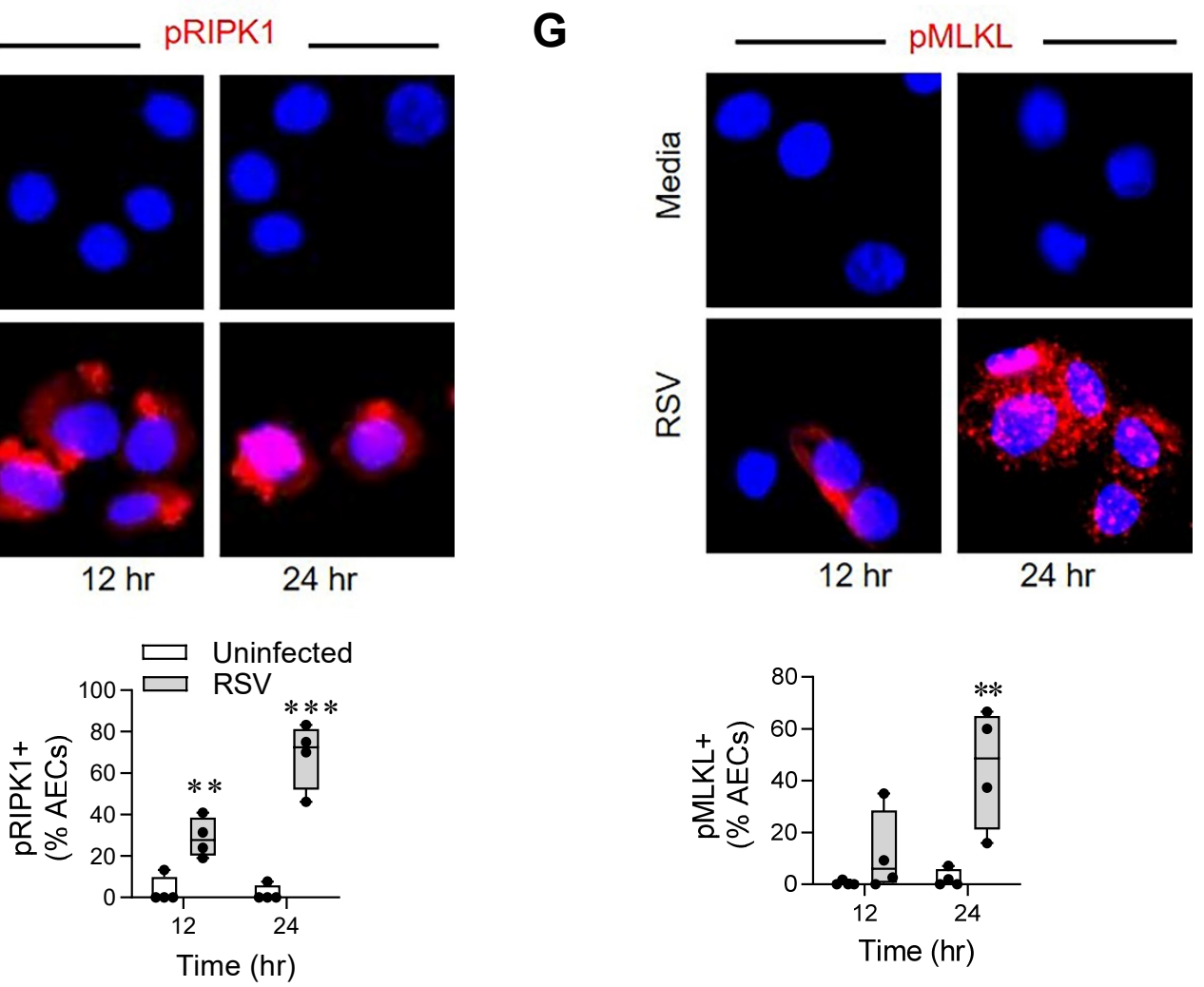


\section{Figure 2}

A

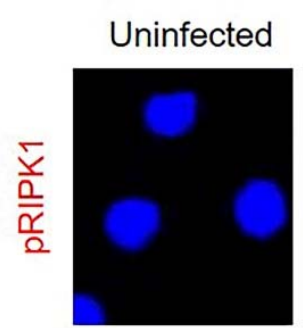

RSV
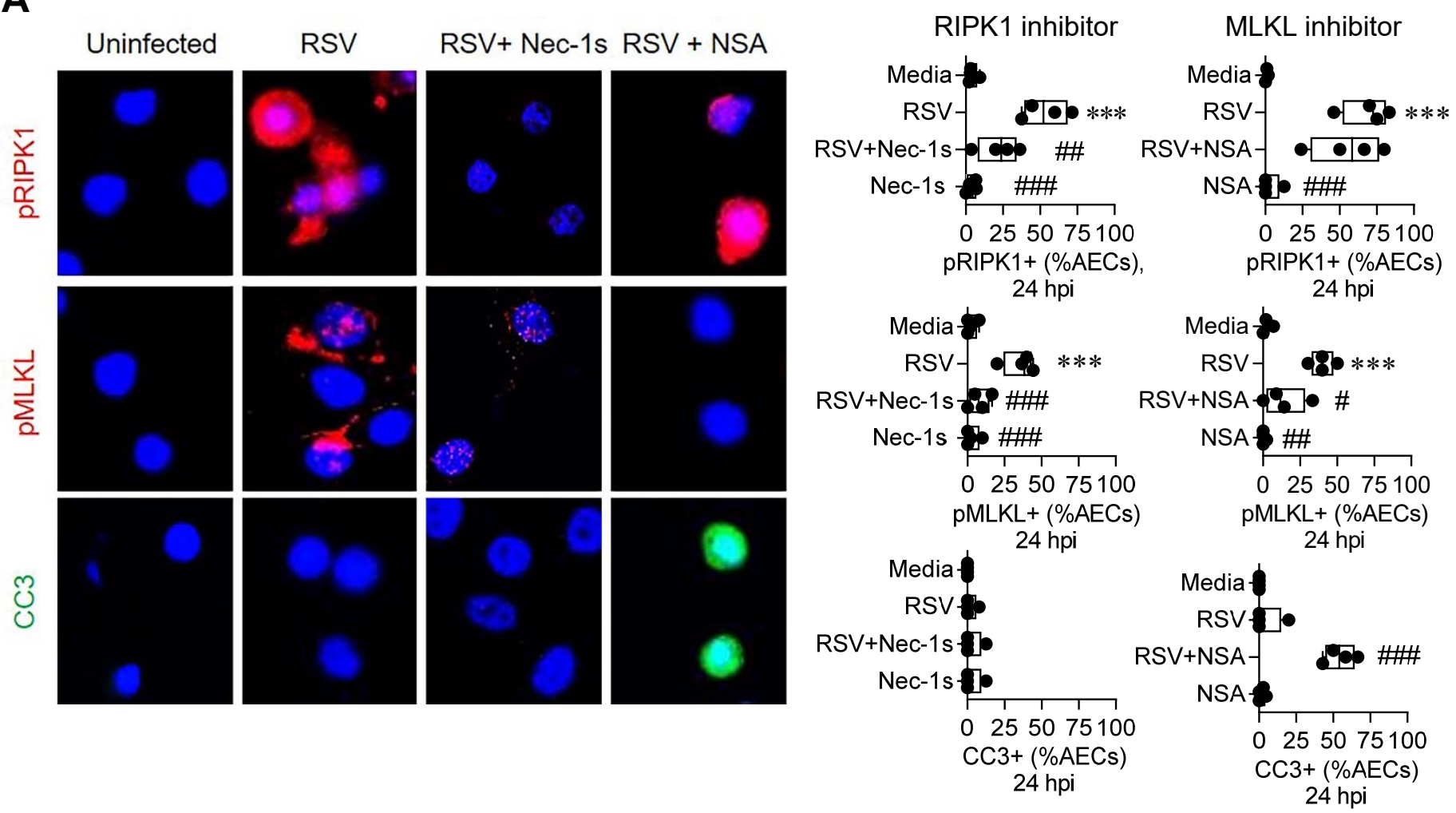

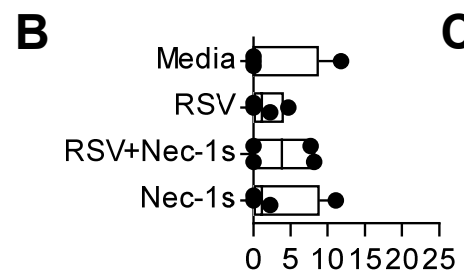

Annexin $\mathrm{V}+(\% \mathrm{AECs})$ $24 \mathrm{hpi}$

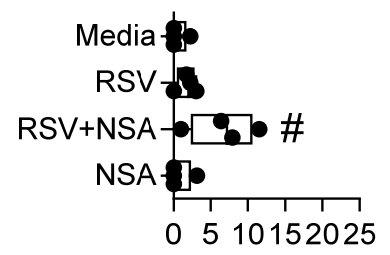

Annexin V+ (\%AECs) $24 \mathrm{hpi}$

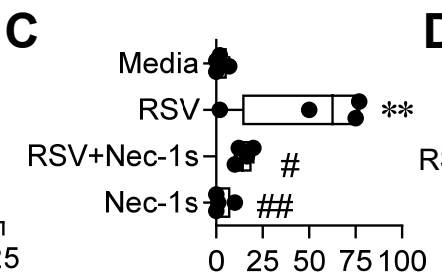

Cyto-HMGB1+ (\%AECs) $24 \mathrm{hpi}$

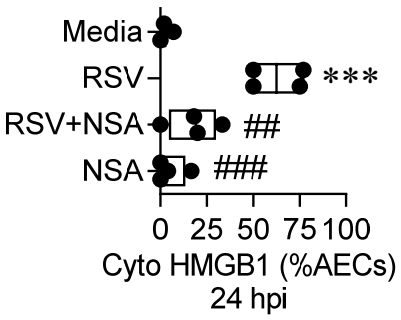

D E Media-J8

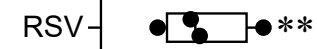

$\mathrm{RSV}+\mathrm{Nec}-1 \mathrm{~s}-\mathbf{4 8 0}$ \# Nec-1s- \# \#

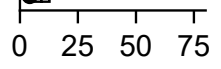
HMGB1 (ng/ml) $24 \mathrm{hpi}$

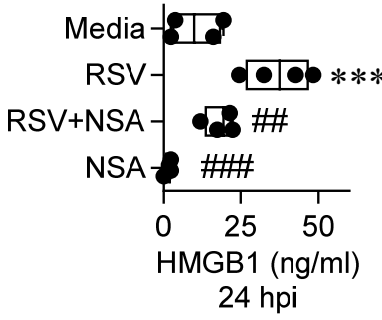

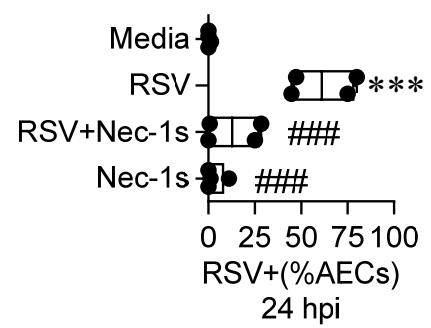

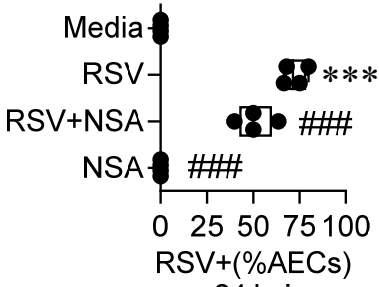

$24 \mathrm{hpi}$ 


\section{Figure 3}

A

B
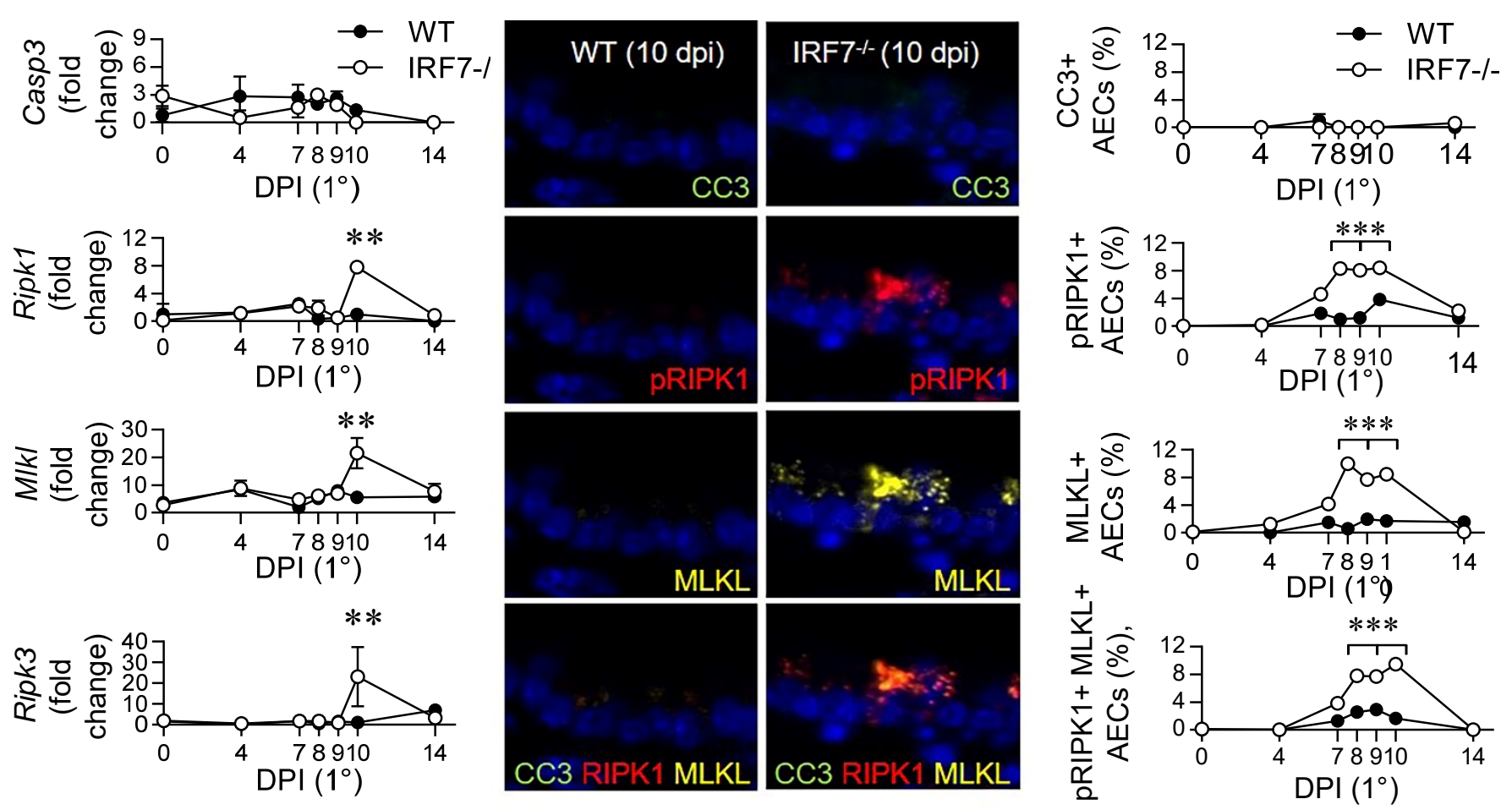

C
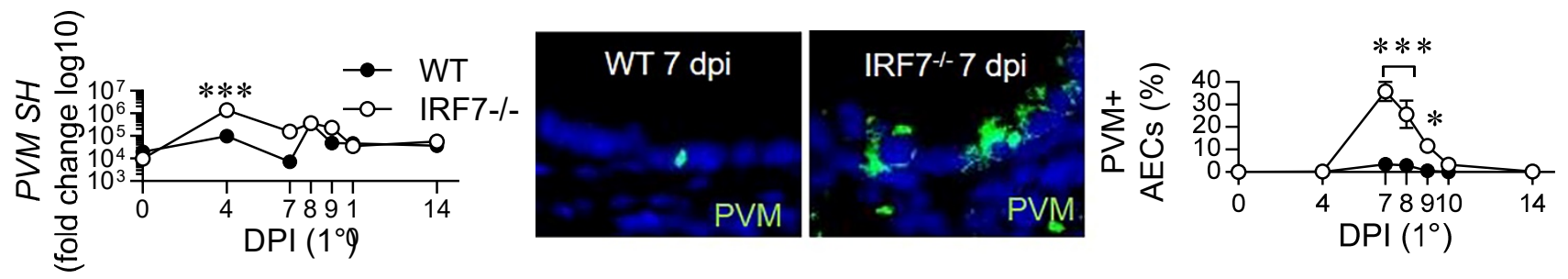


\section{Figure 4}

A
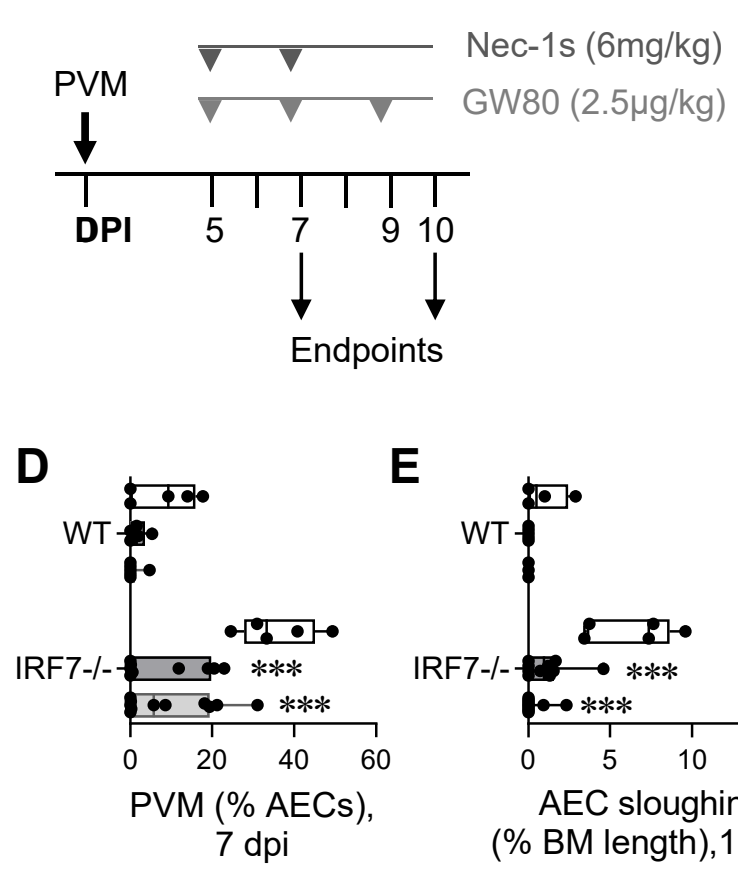

G
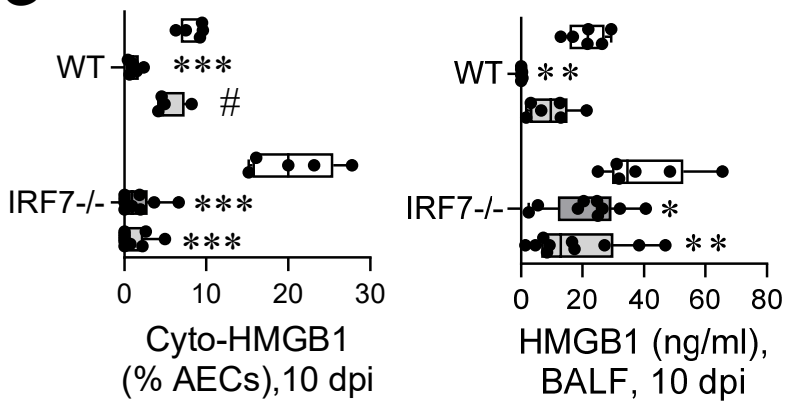

B

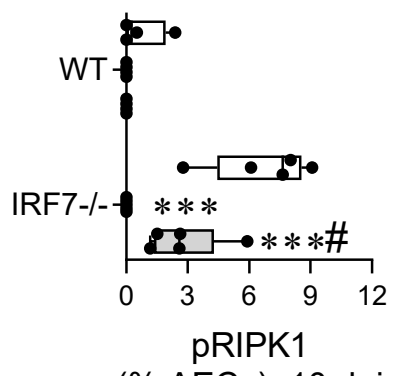

(\% AECs), $10 \mathrm{dpi}$

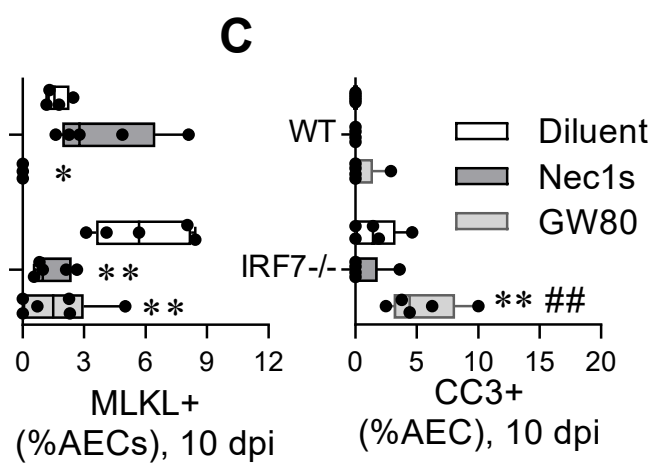

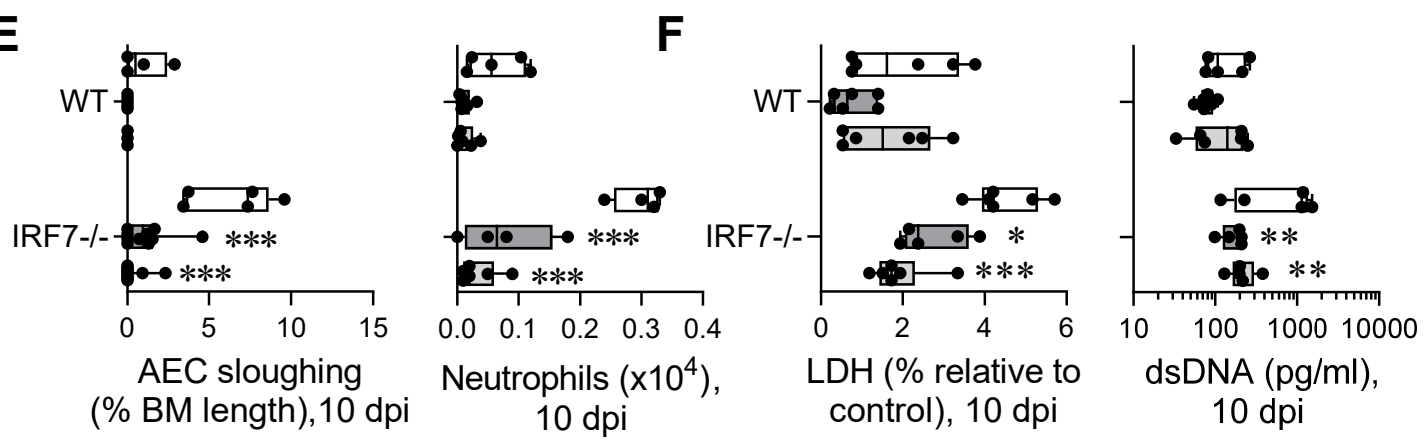
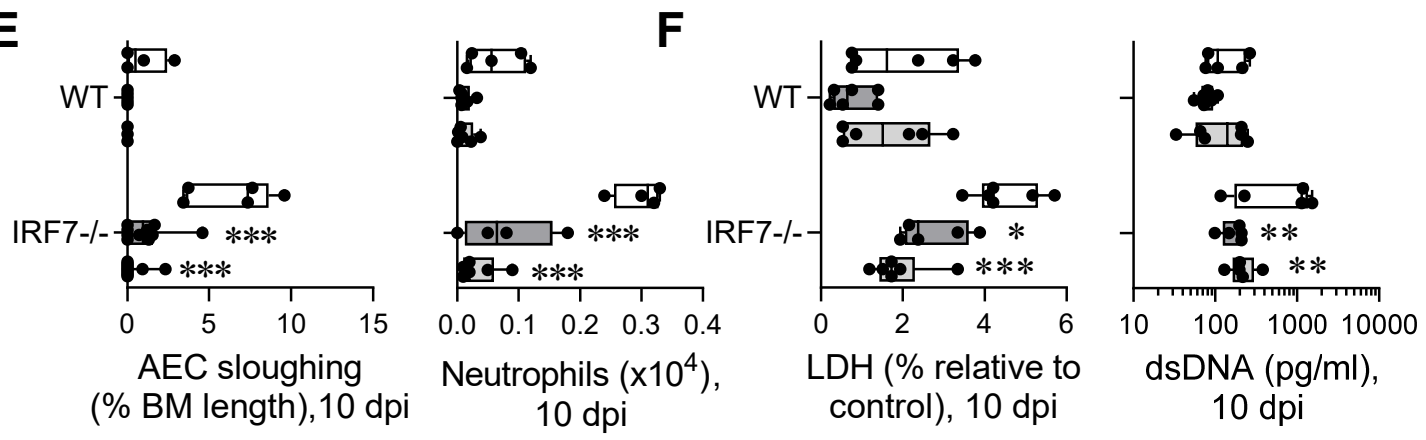


\section{Figure 5}

A

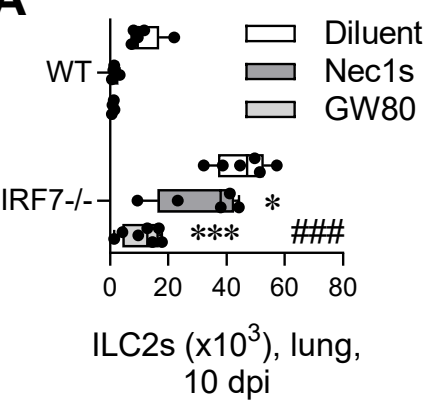

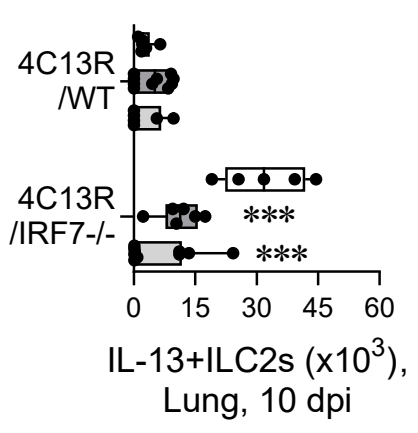

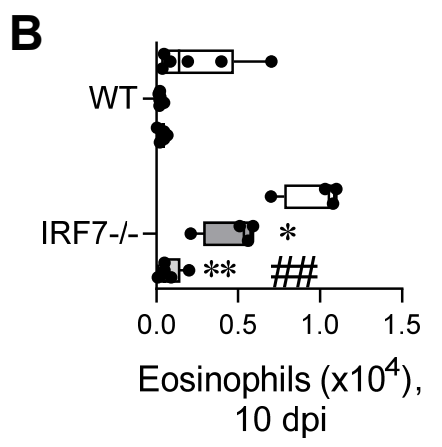

C
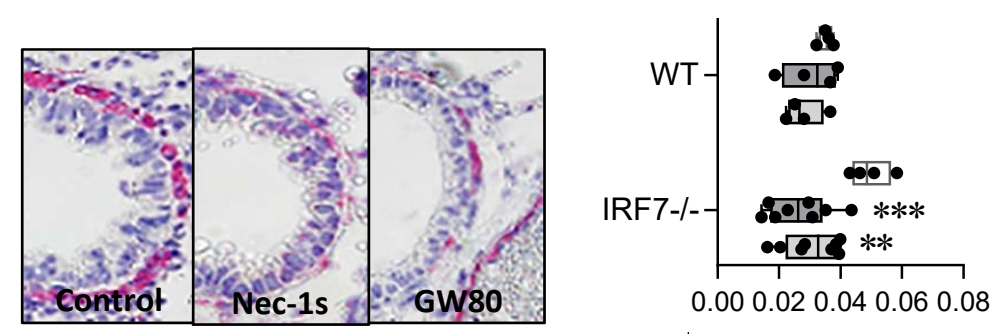

$\sqrt{ }$ ASM area/BM length, $10 \mathrm{dpi}$
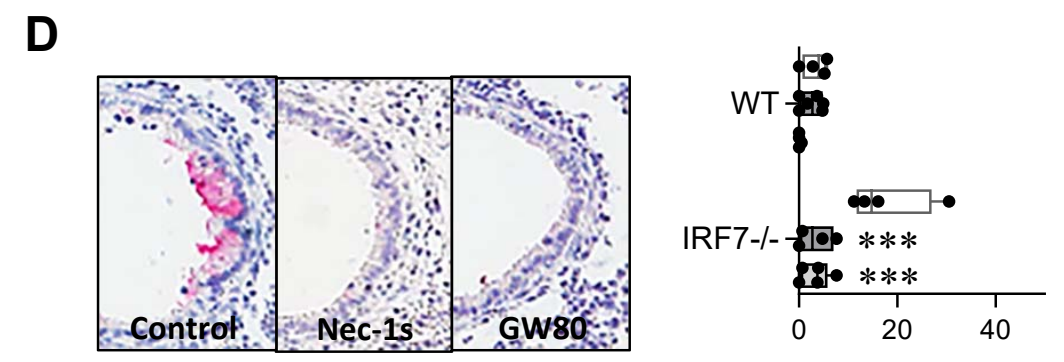

Muc5ac+ (\%AECs), $10 \mathrm{dpi}$ 
Figure 6

A
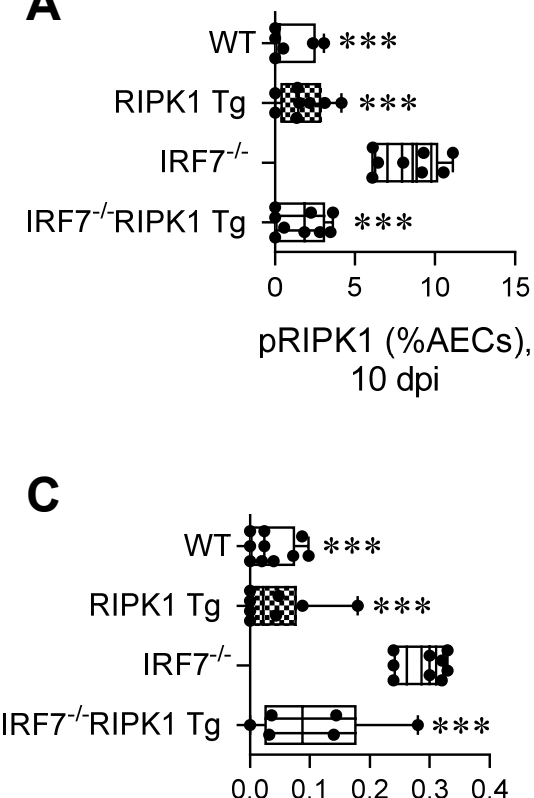

Neutrophils $\left(x 10^{4}\right)$, BALF, $10 \mathrm{dpi}$

E

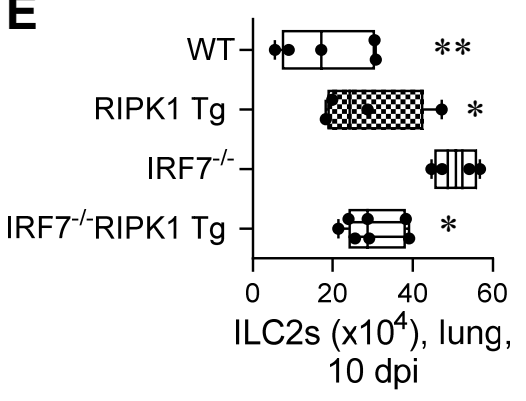

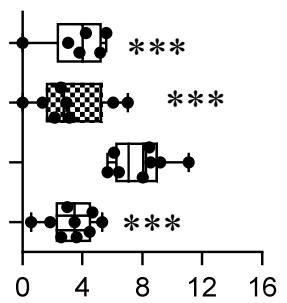
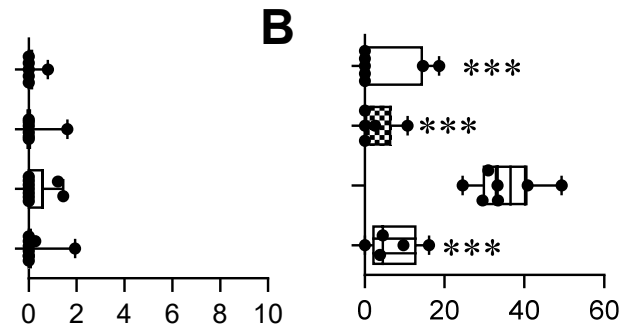

$\mathrm{MLKL}+(\% \mathrm{AECs})$, $10 \mathrm{dpi}$

CC3+ (\%AECs), $10 \mathrm{dpi}$

PVM+ (\%AECs),

$7 \mathrm{dpi}$

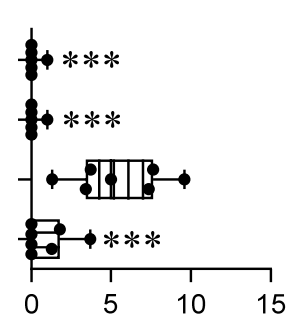

AEC Sloughing (\% BM length), 10 dpi
D

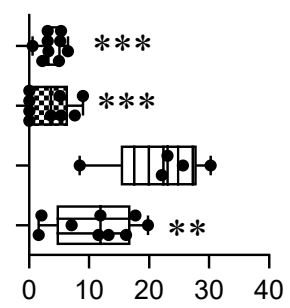

Cyto-HMGB1

(\% AECs), $10 \mathrm{dpi}$

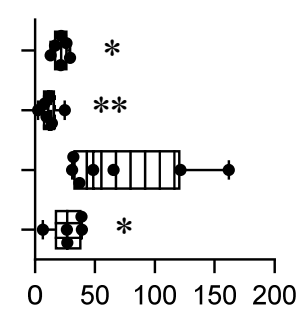

HMGB1 (ng/ml),

BALF, $10 \mathrm{dpi}$

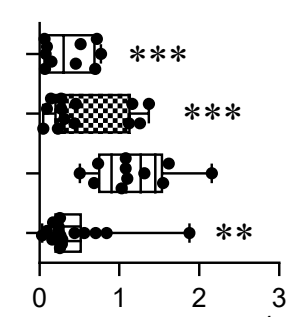

Eosinophils $\left(\times 10^{4}\right)$, BALF, 10 dpi
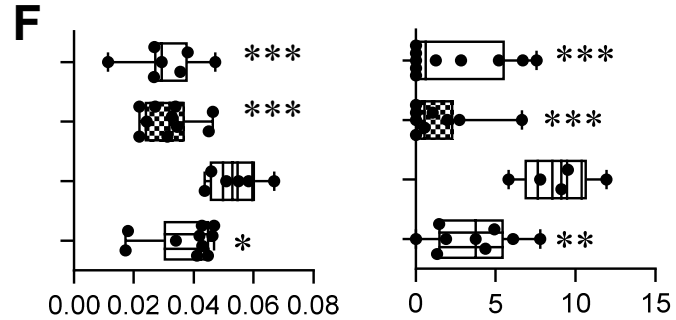

$\sqrt{ }$ ASM area/BM length, Muc5ac+ (\%AECs), $10 \mathrm{dpi}$

$10 \mathrm{dpi}$ 


\section{Figure 7}

A
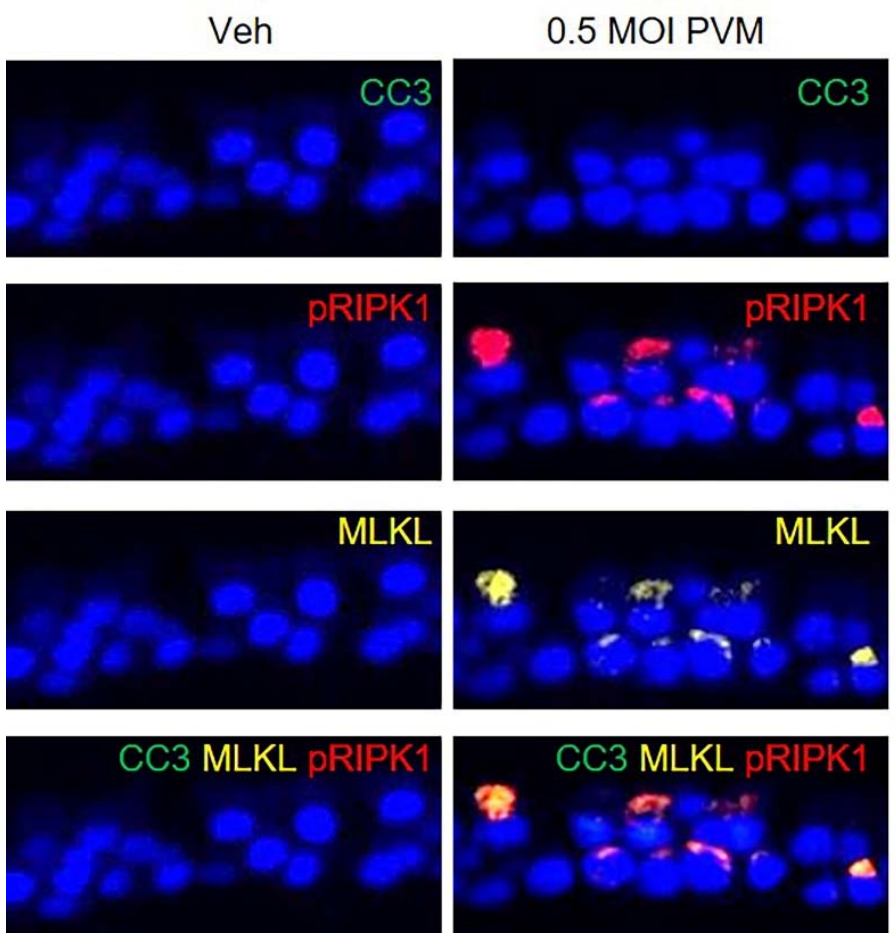
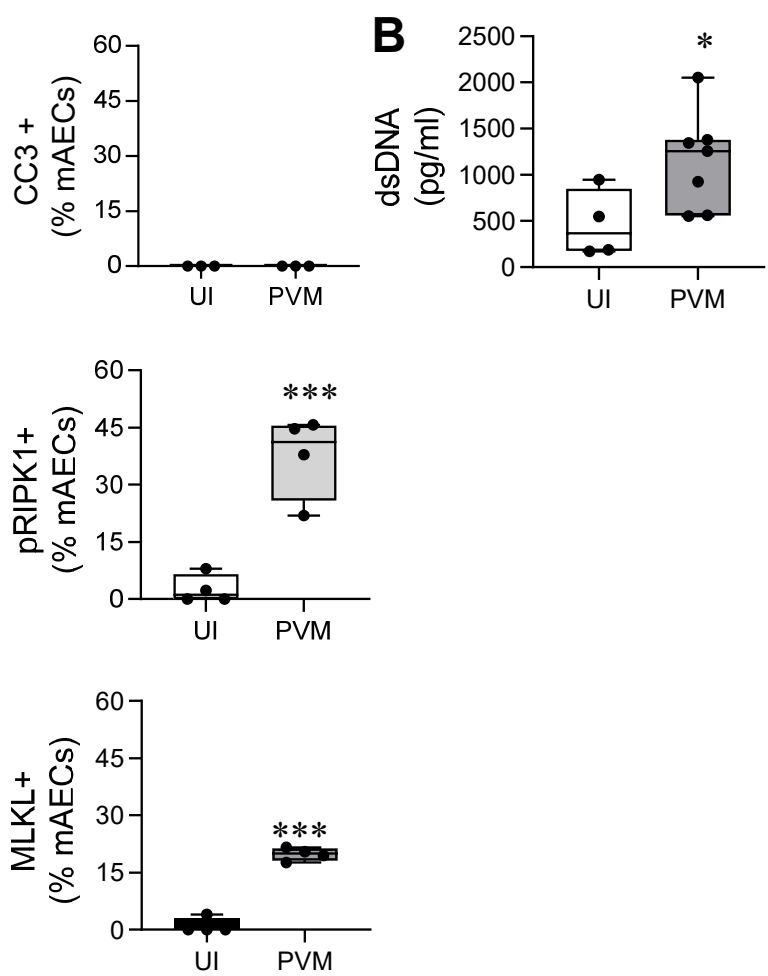

C
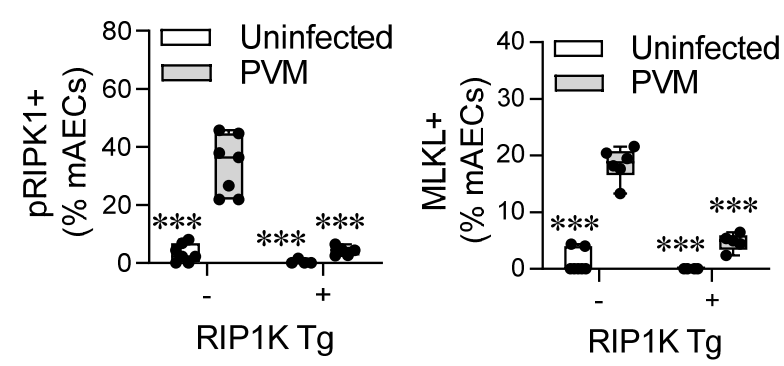

E

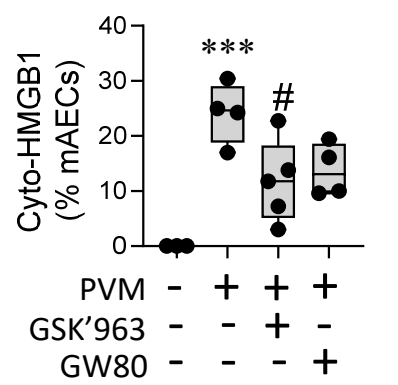

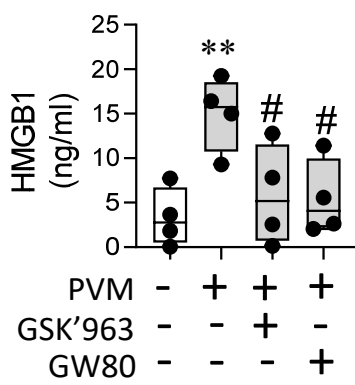

D
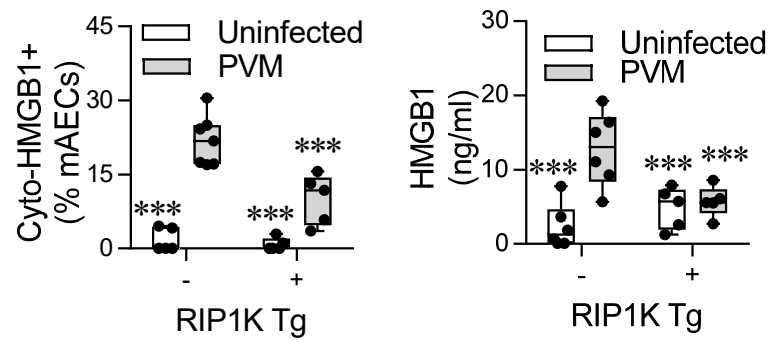

$\mathbf{F}$

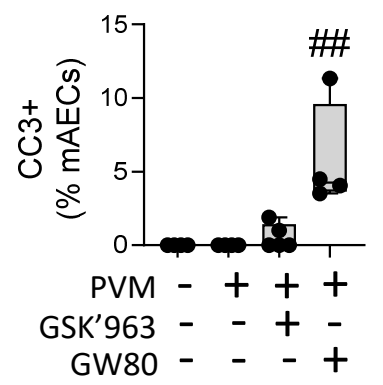




\section{Figure 8}

A

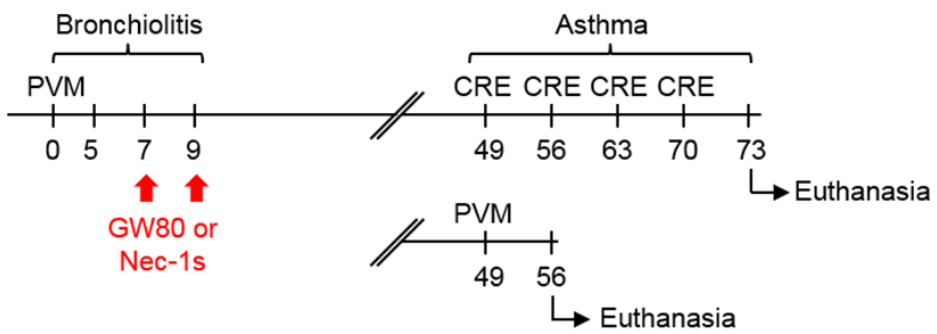

B
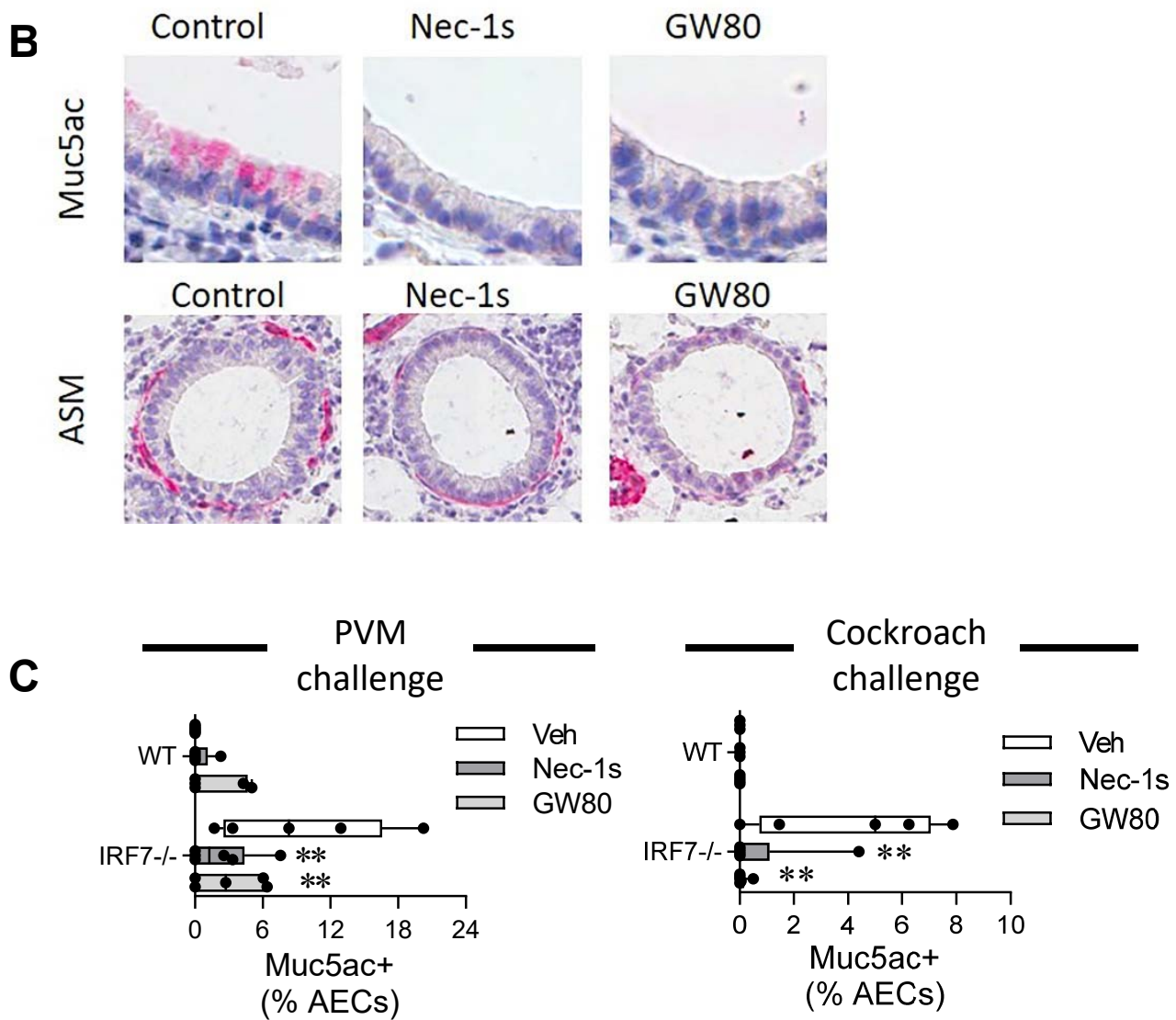

D

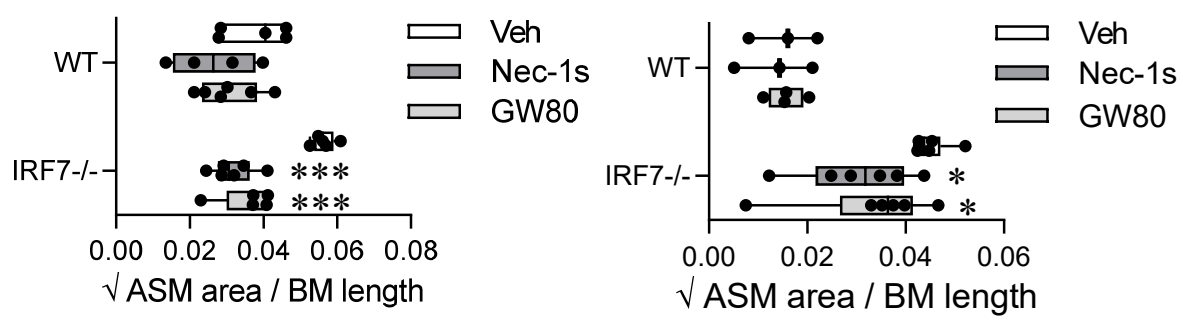

E
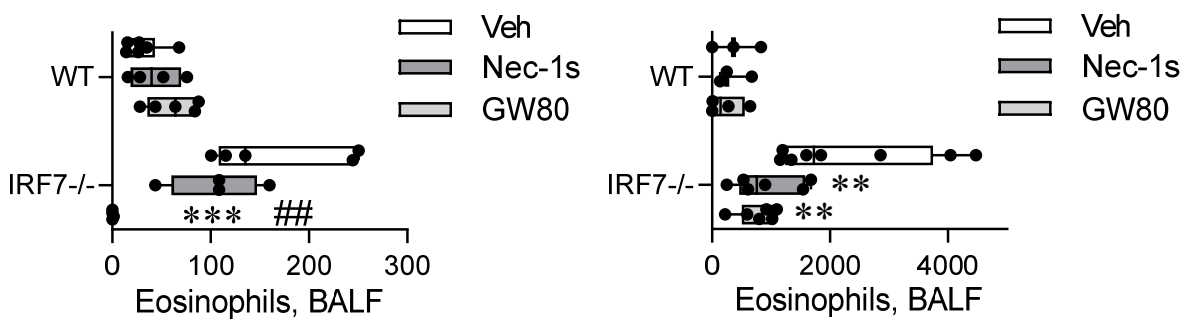


\section{Online Data Supplement}

RSV Infection Promotes Necroptosis and HMGB1 Release by Airway Epithelial Cells

Jennifer Simpson, Zhixuan Loh, Md Ashik Ullah, Jason P. Lynch, Rhiannon B. Werder, Natasha Collinson, Vivian Zhang, Yves Dondelinger, Mathieu J.M. Bertrand, Mark L. Everard, Christopher C. Blyth, Gunter Hartel, Antoon J. Van Oosterhout, Peter J. Gough, John Bertin, John W. Upham, Kirsten M. Spann, Simon Phipps. 


\section{Materials and Methods.}

\section{Human subjects and nasopharyngeal samples.}

Samples were prospectively collected from 2-year-old children (IQ range 1.25 to 3.86) presenting with acute respiratory infection to the Princess Margaret Hospital Emergency Department. Ethical approval for the study was obtained from the ethics committees of Princess Margaret Hospital for Children (1673/EP), the South Metropolitan Area Health Service, and the Western Australian Aboriginal Health Information and Ethics Committee. Bilateral mid turbinate nasal swabs were collected using flocked swabs (Copan Diagnostics Inc, Murrieta, CA). The swab was gently inserted into the nostril until resistance was felt. The swab was rotated several times against the nasal wall. On removal, swabs were inserted into a commercial viral transport media (UTMTM Viral Transport Media; Copan Diagnostics Inc, Murrieta, CA). All samples were frozen at $-80^{\circ} \mathrm{C}$ prior to measurement of $\mathrm{HMGB} 1$ concentration using a commercially avilable ELISA (Chondrex, Redmond, WA, US). Nasopharyngeal samples were tested by polymerase chain reaction (PCR) assay for respiratory viruses.

\section{hAEC culture and treatment}

Human AECs from healthy paediatric (age 2-3 years) donors (ID 28195, 28563, 28385, and 29055) were obtained commercially (Lonza). For all experiments, with the exception of Supplemental Figure E2, the cells were grown in a submerged culture system. In Supplemental Figure E2, the hAECs were differentiated at air-liquid interface (ALI) as previously described (1), and treated with NSA $(10 \mu \mathrm{M})$ or Nec-1s $(2.2 \mathrm{mM})$ for 1 hour prior to RSV infection. Cells were incubated with RSV A2 (MOI 1) for 4 hours, whereafter the inoculum was washed off and fresh media added. At 24 hpi, cells were fixed with neutral buffered $10 \%$ formalin solution (Sigma) for 15 minutes. Paraffin-embedded sections of the ALI membranes were prepared as previously described (1). 


\section{Bronchoalveolar lavage fluid (BALF)}

PBS was washed through the lungs using an adaptor inserted into the trachea. The solution was collected and centrifuged at $5000 \mathrm{rpm}$ to separate cells and supernatant. The supernatant was stored at $-20^{\circ} \mathrm{C}$ prior to quantification of cytokine production by ELISA or CBA. Cells were treated with Gey's red blood cell lysis buffer to remove erythrocytes. The remaining leukocytes were counted using a haemocytometer and flow cytometry performed as described below.

\section{Flow cytometry}

Lung cells were mashed through a cell strainer and red blood cells lysed with Gey's red blood cell lysis buffer. Cells were seeded into a U-bottom 96 well plate at $10^{6} /$ well, and pre-incubated with anti-Fc $\gamma$ RIII/II ('Fc-block') in PBS/1\% FCS medium prior to a 30 minute incubation with one or more of the following fluorochrome-labelled antibodies (BD Biosciences unless otherwise stated). ILC2s defined as lineage-, ST2+, CD90.2+, CD25+. Eosinophils defined as SigF+, CD3-, B220-, MHCII- and neutrophils defined as CD3-, B220-, CD11b+, Ly6G+ Antibodies used: CD11c-FITC (Miltenyi), SiglecH-AF647, B220-V500, CD11b-PerCP Cy5.5. Ly6G-AF488, Siglec-F-APC, B220-PE, CD11b-PerCP Cy5.5, CD3-PE, MHCII-APC Cy7 CD11c-FITC (Miltenyi), CD45R-AF488 (Miltenyi), CD3-AF488 (Miltenyi), CD11c-AF488 (Miltenyi), CD2-AF488 (Miltenyi), Gr-1-AF488 (Miltenyi), CD11b-AF488 (Miltenyi), CD90.2-APC-Cy7 and CD25-BV650. After three washes in PBS/2\% FCS medium cells were analysed using a BD LSR Fortessa x-20.

\section{Cytokine analysis}

The concentration of IL-33 (R \& D systems, Minneapolis, MN, US), IL-5 (BD Biosciences, San Jose, CA, USA), eotaxin-2 (R \& D systems, Minneapolis, MN, US) and HMGB1 
(Chondrex, Redmond, WA, US) expression in BALF and/or lung homogenates was analysed by ELISA according to the manufacturer's protocol. Cytokine bead array (CBA) was used to measure type 1 IFN, TNF $\alpha$ and IL-13 (BD) as per the manufacturer's instructions. Double stranded (dsDNA; Invitrogen) was measured according to the manufacturer's protocol. Lactate dehydrogenase (LDH; (Thermofisher) was measured according to the manufacturer's protocol. Data is presented as percentage of the positive control provided in the kit.

\section{Immunohistochemistry and Immunofluorescence}

Paraffin-embedded sections were prepared as previously described (2). Slides were dehydrated using xylene and ethanol washes before antigen retrieval using citrate buffer. Lung sections were permeabilized using $0.5 \%$ Triton in PBS for 10 minutes. Non-specific binding was blocked with $10 \%$ normal goat serum in PBS. Primary antibodies used:anti-PVM (kindly provided by Dr Ulla Buchholz, Laboratory of Infectious Diseases, National Institute of Allergy and Infectious Diseases, 1:100), anti-HMGB1 (Abcam, ab18256; 1:400 dilution), anti- $\alpha-$ smooth muscle actin (Sigma, clone 1A4; 1:800), anti-pRIPK1 (Ser166) (kindly provided by GSK; 1:450), anti-MLKL (Merk Millipore, clone 3H1; 1:200), anti-cleaved caspase-3 (Asp 175) conjugated-488 (CST, CST9669; 1:200). Mouse lung were incubated overnight at room temperature with the primary antibody. For bright-field microscopy, sections were washed 3 times in PBS/Tween 20 before 60 minutes of incubation with either anti-rabbit IgG- alkaline phosphatase (AP) (Sigma; 1:200), anti-mouse IgG-AP (Sigma; 1:200) or anti-rat IgG-AP (Sigma; 1:200). After washing, colour was developed with Fast Red substrate (Sigma). Sections were counterstained with hematoxylin before mounting with Glycergel (Dako). Quantitative analyses were conducted with Aperio Image Scope software (Aperio, Vista, Calif). Images were captured at $\times 20$ or $\times 40$ magnification with an Olympus microscope (model BX51), a digital camera (Olympus DP70), and DP software (Olympus, Center Valley, Pa). 
For detection by immunofluorescence (pRIPK1, MLKL), slides were incubated at room temperature overnight as described above, washed with $0.5 \%$ Triton in PBS, then incubated with goat anti-rabbit-AF555 (Sigma; 1:500) and goat anti-rat 647 (Sigma; 1:500) respectively for 1 hour at room temperature. Slides stained with cleaved caspase-3-488 were not incubated with a secondary antibody. All slides were counterstained using DAPI (Sigma; 1:10,000), mounted with fluorescent mounting media (DAKO) and imaged on a Diskovery Spinning Disk confocal microscope (Nikon) or a Zeiss 780-NLO Point scanning confocal (Zeiss).

To quantify PVM, HMGB1, MLKL and pRIPK1-positive AECs, the fraction of immunoreactive AECs was counted in a minimum of three airways, and the mean value for each mouse presented in the graph. To enumerate ASM area, Aperio IMageScope (Leica Biosystems Inc, IL, USA) software was used to measure the area $(\mu \mathrm{m} 2)$ of $\alpha$-smooth muscle actin immunoreactivity. The square root of this value was divided by the length of the basement membrane $(\mu \mathrm{m})$. For each mouse, three airways were counted and the mean value for each mouse presented in the graph, as described previously $(3,4)$.

For immunofluorescent detection of antigens in hAECs, the cells were incubated with antihuman pMLKL (S358) (Abcam, ab187091; 1:200), anti-human pRIPK1 (Ser166; same clone as used on mouse tissue), anti-human cleaved caspase-3 (Asp 175) conjugated-488 (CST, CST9669; 1:200) and anti-human HMGB1 (R\&D, MAB1690; 1:300). Secondary antibodies and other procedures were used as described above. For Propidium iodide (PI) (Thermofisher; 1:1000) and annexin V (BD Biosciences, BD 550475; 1:200) staining, live cells were incubated for 10 or 30 minutes respectively before washing with distilled water and mounting as described above. Quantification for all antibodies consisted of determining the number of immunoreactive 
cells as percentage of total cells. 100 to 300 cells were counted per data point, representing approximately $30 \%$ of the total cell count.

\section{Quantitative real time PCR}

Total RNA was isolated from the inferior right lung lobe with TriReagent solution (Ambion) followed by phenol-chloroform extraction. DNAse digestion was performed with Turbo DNAse (Ambion) as described previously (5). Reverse transcription was performed using MMLV reverse transcriptase and random primers (Invitrogen). qRT-PCR was performed with SYBR Green (Life Technologies). Primer sequences are shown in Table E1. Expression values were normalized relative to the housekeeping genes Hprt (mouse cells) or $\beta$-actin (human cells) and expressed as fold change relative to naïve (vehicle treated) mice of the same genotype using the 2- $\Delta \Delta \mathrm{CT}$ formula. 


\section{Figure legends:}

\section{Supplemental Figure E1: Inhibition of RIPK1 kinase activity or MLKL reduces viral} load

Submerged human AECs were were pre-treated with cell death inhibitors then infected with RSV (MOI of 1). Endpoints were assessed at 24 hours post infection. (A) Quantification of cleaved caspase-3 (CC3) and RSV positive cells.

(B) RSV gene expression.

(C) IFN $\lambda 2$ gene and protein expression.

(D) IFN $\lambda 1$ and IFN $\lambda 3$ gene expression.

(E) IFN $\beta$ gene expression.

Data are representative of $n=2$ experiments with four donors in each group and are presented as box-and-whisker plots showing quartiles (boxes) and range (whiskers). Data were analyzed using one-way ANOVA with Dunnette's post hoc test. *, $\mathrm{P}<0.05$ and **, $\mathrm{P}<0.01$ are compared to RSV-infected hAECs (A) or uninfected hAECs (B-E). \#, P <0.05 and \#\#, P $<0.01$ are compared to MLKL-inhibitor treated RSV infected hAECs (A) or RSV-infected hAECs (B-E).

\section{Supplemental Figure E2: Inhibition of RIPK1 kinase activity or MLKL lowers viral} load and HMGB1 translocation and release in differentiated AECs.

Air-liquid interface-differentiated human AECs were infected with RSV (MOI 1). Expression of HMGB1, necroptosis proteins and cell death markers were assessed at 24 hours post infection. (A) Expression of dsDNA in supernatant and Quantification of cleaved caspase-3 (CC3) positive AECs.

(B) Representative images (x200 magnification) of pRIPK1 and pMLKL (green). Quantification of pRIPK1 and pMLKL positive AECs. 
(C) Quantification of cytoplasmic HMGB1 positive AECs. HMGB1 protein expression in basal supernatant.

(D) Quantification of RSV positive AECs.

Data are representative of $n=2$ experiments with four donors in each group and are presented as box-and-whisker plots showing quartiles (boxes) and range (whiskers). Data were analyzed using one-way ANOVA with Dunnett's post hoc test. *, $\mathrm{P}<0.05$; **, $\mathrm{P}<0.01$ and ***, $\mathrm{P}$ $<0.001$ are compared to uninfected hAECs. \#, $\mathrm{P}<0.05$ and \#\#, $\mathrm{P}<0.01$ are compared to RSVinfected hAECs.

\section{Supplemental Figure E3: Absence of IRF7 or high viral load predisposes to elevated cell} death and necroptosis during acute viral infection.

Neonatal WT and IRF7 ${ }^{-/}$mice were infected with PVM (2 or 100 pfu)at 7 days of age. Endpoints were assessed over time.

(A) dsDNA, LDH and protein expression in bronchoalveolar lavage fluid (BALF). TNF $\alpha$ protein expression in lung.

(B) Quantification of abnormal nuclei. Red is MLKL.

(C) Representative micrograph (x400 magnification) of MLKL (green) and Phalloidin (cytoskeleton marker) (red). Quantification of apical MLKL positive AECs.

(D) Representative micrograph (x400 magnification) of MLKL (red) and cleaved caspase-3 (green) positive AECs.

(E) Representative micrograph (x400 magnification) of MLKL (red) and PVM (green) positive AECs. Quantification of MLKL expressing PVM-positive AECs.

(F) Quantification of PVM and pRIPK1positive AECs. Quantification of PVM positive and pRIPK1 and MLKL double positive AECs. 
Data are representative of $n=2$ experiments with four to six neonates in each group and are presented as box-and-whisker plots showing quartiles (boxes) and range (whiskers). Data were analyzed using two-way ANOVA with Sidak's post hoc test (A), Student's t test (B,C, E) or one-way ANOVA with Dunnett's post hoc test. *, P <0.05; **, P <0.01; ***, P <0.001 and $* * * *, \mathrm{P}<0.0001$ are compared to PVM infected ( $2 \mathrm{pfu}) \mathrm{WT}$ mice.

\section{Supplemental Figure E4: Inhibition of RIPK1 kinase activity or MLKL alter cytokine expression during acute viral infection.}

Neonatal WT and IRF7 ${ }^{-/-}$mice were treated with either a RIPK1 inhibitor (Nec-1s) or MLKL inhibitor (GW80) then infected with PVM (2 pfu) at 7 days of age. Expression of TNF $\alpha$ and IL-33 was determined at 10 days post infection.

(A) $\mathrm{TNF} \alpha$ protein expression in lung.

(B) IL-33 protein expression in BALF.

Data are representative of $n=2$ experiments with four to six neonates in each group and are presented as box-and-whisker plots showing quartiles (boxes) and range (whiskers; a-k). Data were analyzed using one-way ANOVA with Dunnett's (A) or two-way (B) ANOVA with Sidak's post hoc test. **, $\mathrm{P}<0.01$ is compared to untreated (diluent) WT or IRF7 ${ }^{-/-}$infected mice.

\section{Supplemental Figure E5: Inhibition of pRIPK1 by GSK'963 reduces alarmin release,} bronchiolitis, Th2 inflammation and airway remodelling.

Neonatal WT and IRF7 ${ }^{-/-}$mice were treated with a RIP1K inhibitor (GSK'963) then infected with PVM (2 pfu) at 7 days of age. Endpoints were assessed at 7 and 10 days post infection.
(A) Study design.
(B) Quantification of MLKL, cleaved caspase-3 (CC3) and AEC sloughing in AECs. 
(C) Quantification of PVM positive AECs.

(D) Quantification of cyto-HMGB1 and protein expression of HMGB1 and IL-33 in BALF.

(E) ILC2 in lung.

(F) Eosinophils in BALF.

(G) Neutrophils in BALF.

(H) Quantification of ASM area.

Data are representative of $n=2$ experiments with four to six neonates in each group and are presented as box-and-whisker plots showing quartiles (boxes) and range (whiskers; a-k). Data were analyzed using two-way ANOVA with Sidak's post hoc test.*, $\mathrm{P}<0.05$; **, $\mathrm{P}<0.01$ and ***, $\mathrm{P}<0.001$ are compared to inactive enantiomer (control) treated $\mathrm{WT}$ or $\mathrm{IRF} 7^{-/-}$infected mice.

Supplemental Table E1: qPCR primers (Sigma)

\section{Supplementary References}

1. Schagen J, Sly PD, Fantino E. Characterizing well-differentiated culture of primary human nasal epithelial cells for use in wound healing assays. Lab Invest 2018; 98: 1478-1486.

2. Kaiko GE, Loh Z, Spann K, Lynch JP, Lalwani A, Zheng Z, Davidson S, Uematsu S, Akira S, Hayball J, Diener KR, Baines KJ, Simpson JL, Foster PS, Phipps S. Toll-like receptor 7 gene deficiency and early-life Pneumovirus infection interact to predispose toward the development of asthma-like pathology in mice. J Allergy Clin Immunol 2013; 131: 1331-1339 e1310.

3. Lynch JP, Werder RB, Loh Z, Sikder MAA, Curren B, Zhang V, Rogers MJ, Lane K, Simpson J, Mazzone SB, Spann K, Hayball J, Diener K, Everard ML, Blyth CC, Forstner C, Dennis PG, Murtaza N, Morrison M, P OC, Zhang P, Haque A, Hill GR, Sly PD, Upham JW, Phipps S. Plasmacytoid dendritic cells protect from viral bronchiolitis and asthma through semaphorin 4a-mediated T reg expansion. J Exp Med 2018; 215: 537-557. 
4. Werder RB, Zhang V, Lynch JP, Snape N, Upham JW, Spann K, Phipps S. Chronic IL-33 expression predisposes to virus-induced asthma exacerbations by increasing type 2 inflammation and dampening antiviral immunity. J Allergy Clin Immunol 2018; 141 : 1607-1619.e1609.

5. Lynch JP, Werder RB, Simpson J, Loh Z, Zhang V, Haque A, Spann K, Sly PD, Mazzone SB, Upham JW, Phipps S. Aeroallergen-induced IL-33 predisposes to respiratory virus-induced asthma by dampening antiviral immunity. J Allergy Clin Immunol 2016; 138: 1326-1337. 


\section{Supplemental Figure 1}

A

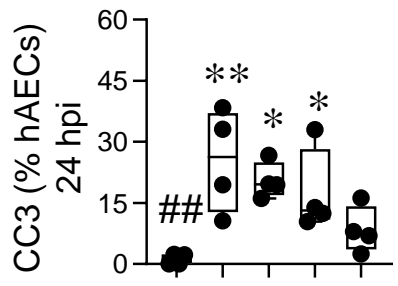

$$
\mathrm{RSV}+++++
$$

MLKLinhr - ++++

Casp 8 inhr $-t_{-}+$

Casp 9 inhr - $-{ }_{-}++$

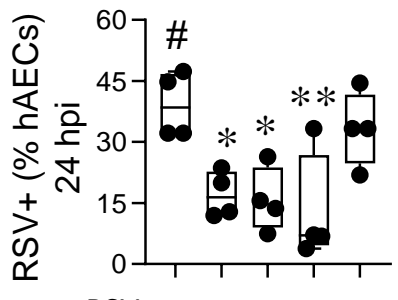

$\mathrm{RSV}+++++$

MLKL inhr - + + + +

Casp 8 inhr - - + - +

Casp 9 inhr - $-{ }_{-}+$
B

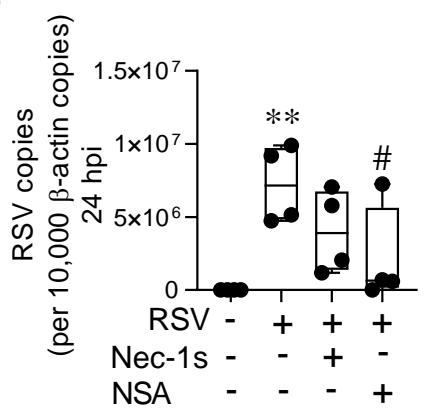

C
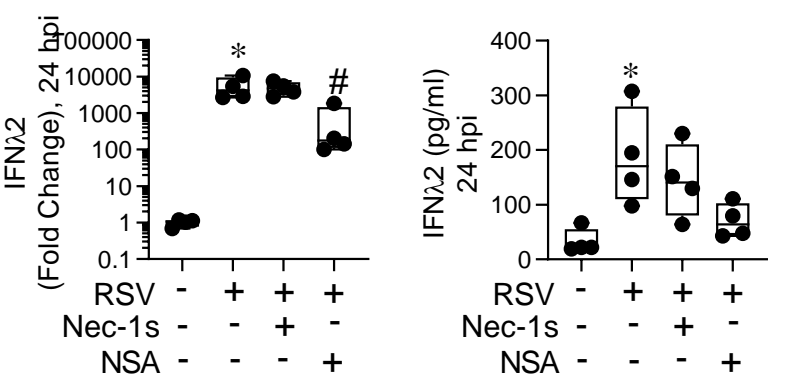

D

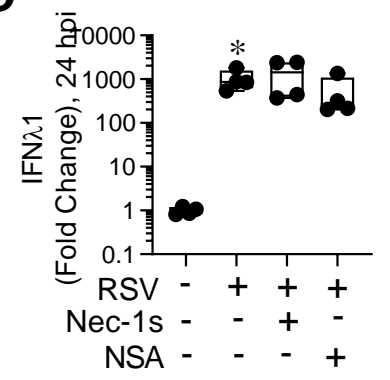

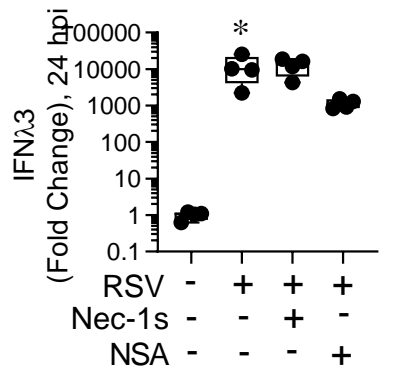

$\mathbf{E}$

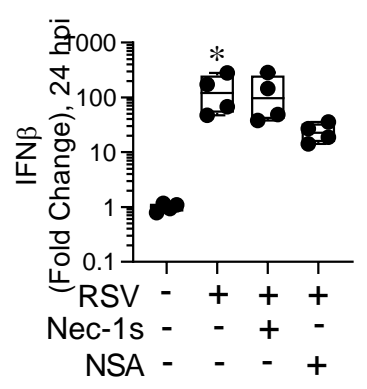




\section{Pssipspofémental Figure 2}

A

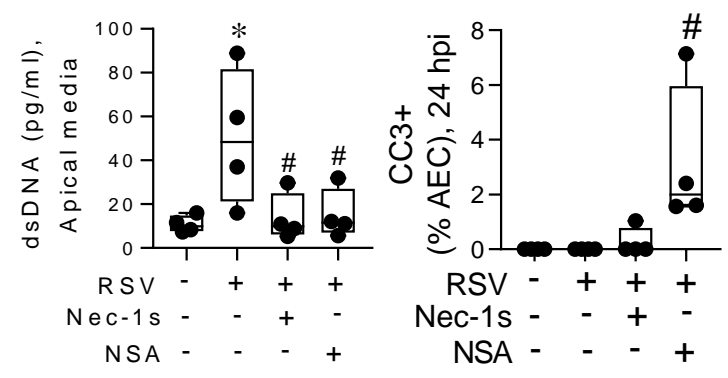

B
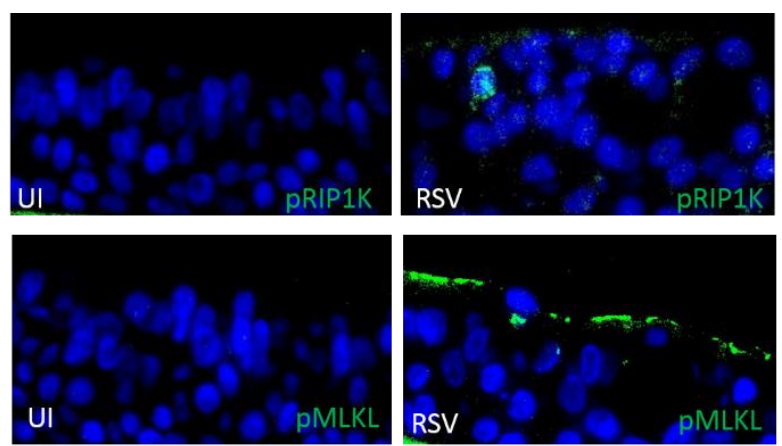

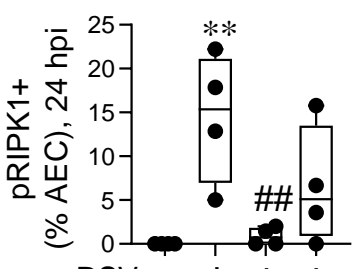

RSV - + + +

Nec-1s - - +-

NSA - - -+

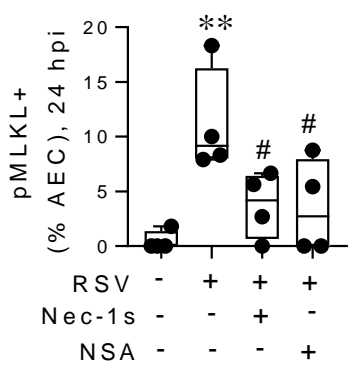

C
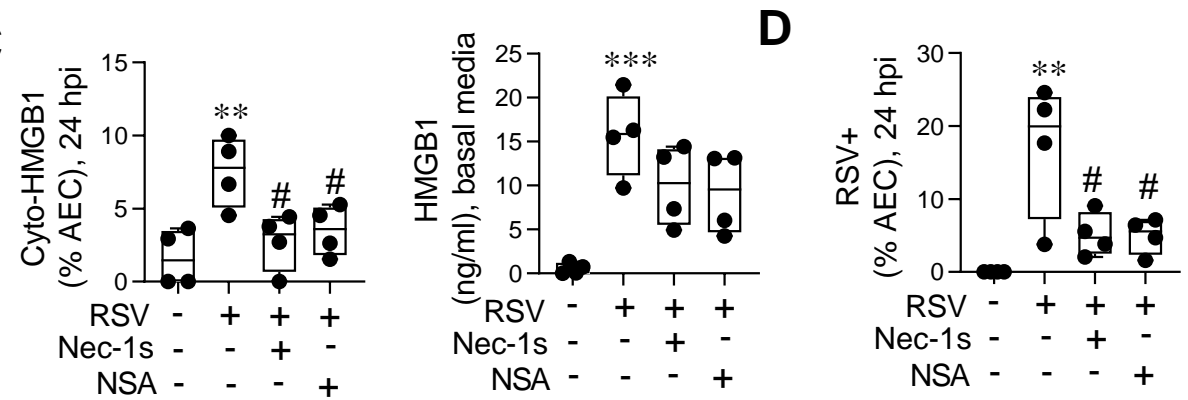
A
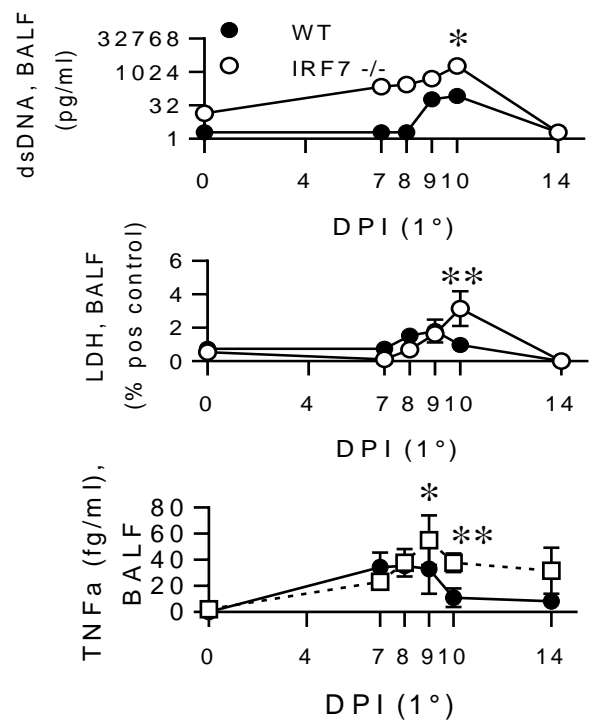

B
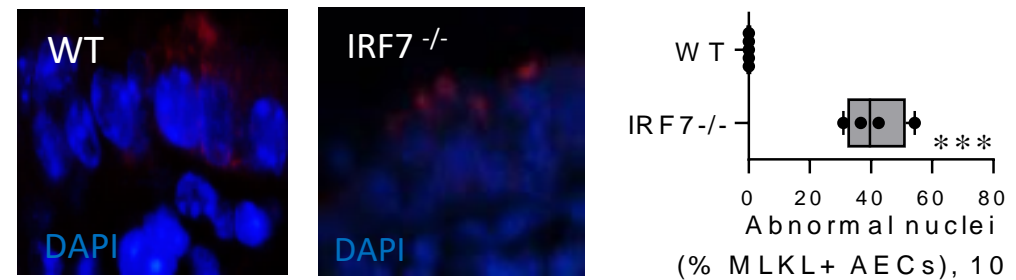

$(\%$ MLKL+AECs), $10 \mathrm{dpi}$

C
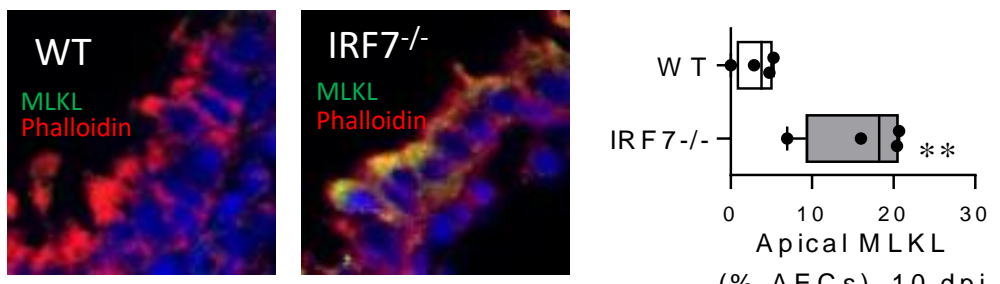

(\% AECs), $10 \mathrm{dpi}$
D

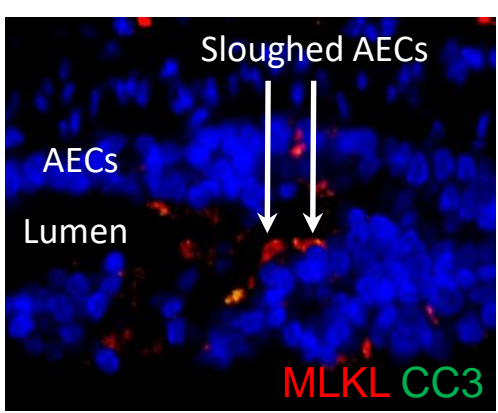

F

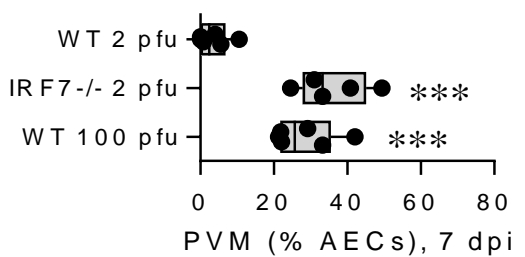

E
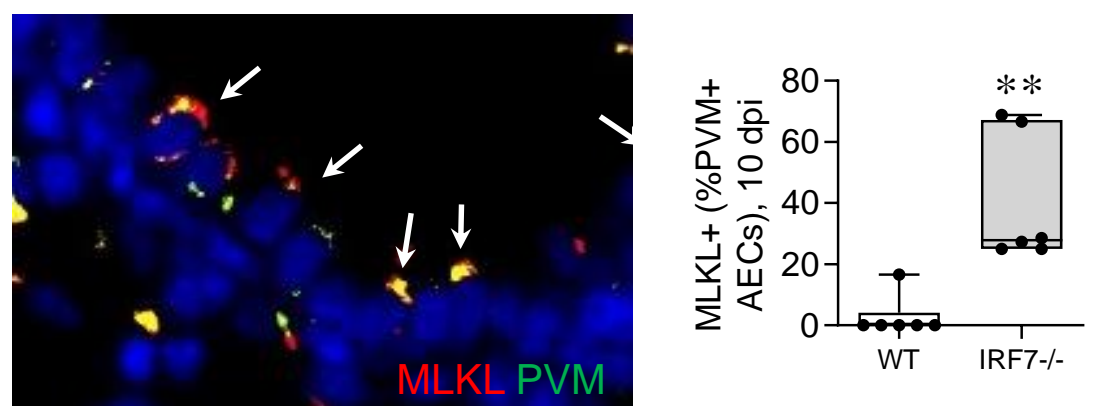


\section{Supplemental Figure 4}

A

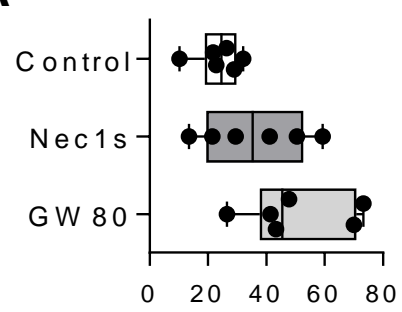

TNF $\alpha(f g / m I), B A L F$ $10 \mathrm{dpi}$
B

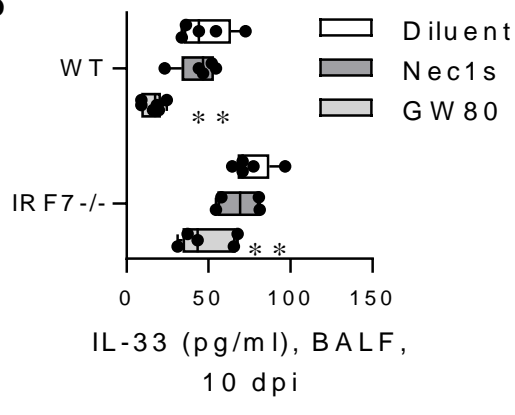


A

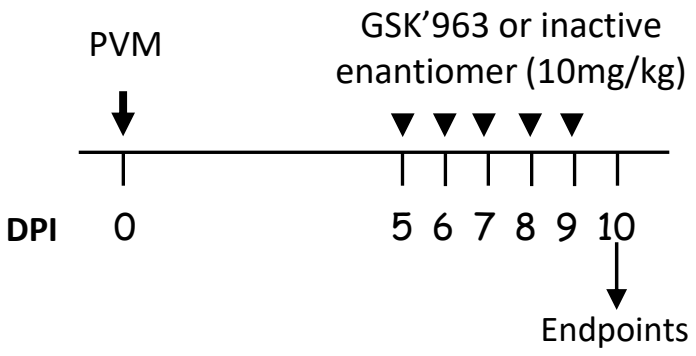

B
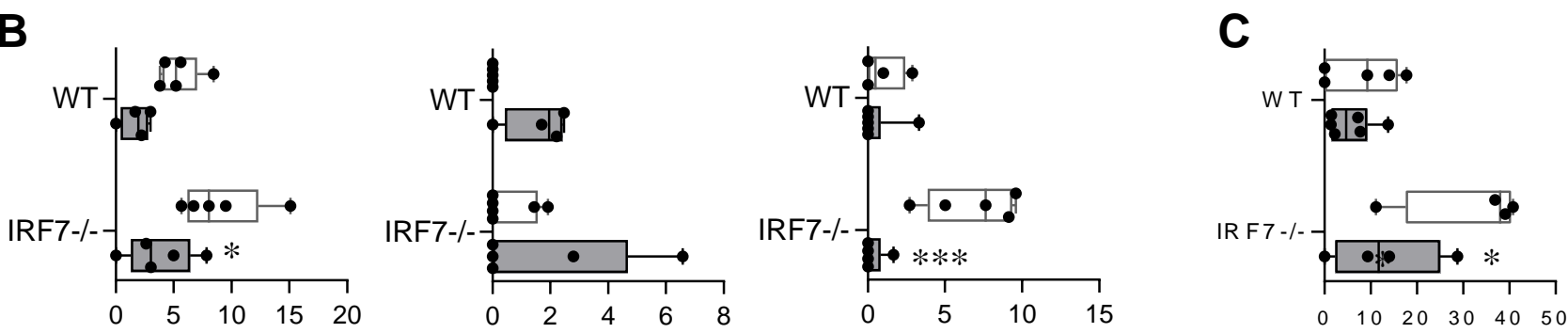

MLKL+ (\% AECs), $10 \mathrm{dpi}$

$\mathrm{CC} 3+(\% \mathrm{AECs})$, $10 \mathrm{dpi}$

AEC sloughing (\% BM length), $10 \mathrm{dpi}$

$\mathrm{PVM}+(\% \mathrm{AECs})$, $7 \mathrm{dpi}$

D
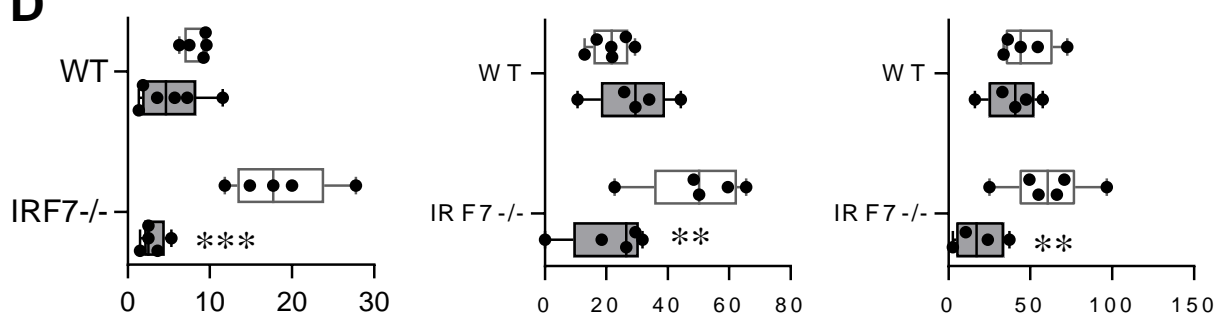

Cyto-HMGB1 (\%AECs), $10 \mathrm{dpi}$

HMGB 1 (ng/m I), BALF $10 \mathrm{dpi}$

IL-33 (pg/m I), BALF $10 \mathrm{dpi}$

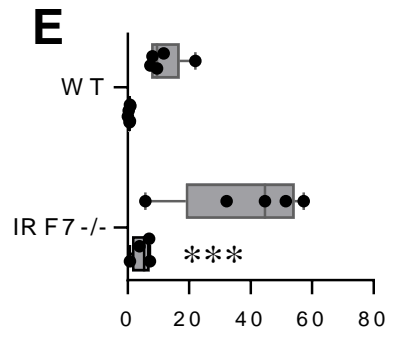

ILC2s $\left(\times 10^{3}\right)$, Lung, $10 \mathrm{dpi}$

$\mathbf{F}$

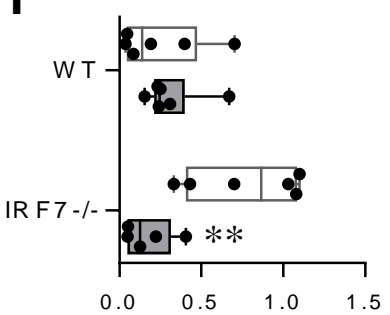

G

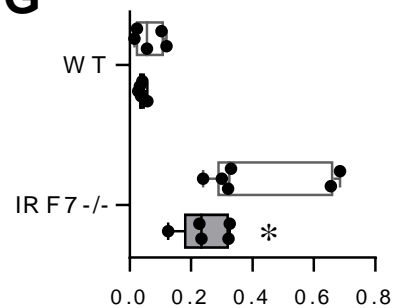

H

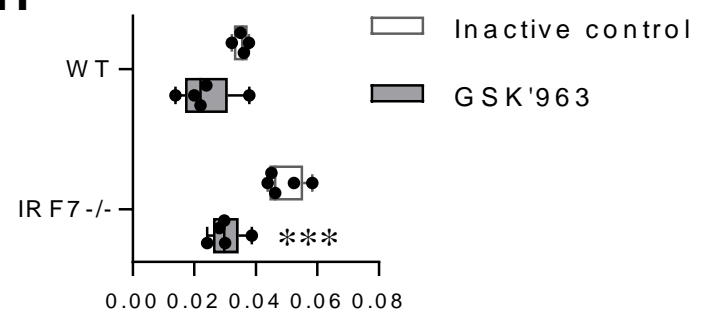

Eosinophils $\left(\times 10^{4}\right)$, BALF, Neutrophils $\left(x 10^{4}\right)$, BALF, $10 \mathrm{dpi}$
$10 \mathrm{dpi}$

$10 \mathrm{dpi}$ 


\begin{tabular}{|c|c|c|}
\hline Gene & Forward Primer & Reverse Primer \\
\hline Mouse Casp3 & TGAATCCACTGAGGTTTTGTTG & TGCTGGTGGGATCAAAGC \\
\hline Mouse Ripk1 & CTCCAACACACCACTTTTGG & CTCCAACACACCACTTTTGG \\
\hline Mouse Ripk3 & TCCCAATCTGCACTTCAGAAC & GACACGGCACTCCTTGGTAT \\
\hline Mouse Mlkl & AGGAACCAGTGGGTCAGGAT & CAAGATTCCGTCCACAGAGGG \\
\hline Mouse Pvm G & GCCTGCATCAACACAGTGTGT & GCCTGATGTGGCAGTGCTT \\
\hline Human RSV & AAGGGATTTTTGCAGGATTGTTT & CTCCCCACCGTAGCATTACTTG \\
\hline Human IFN $\lambda 2$ (IL28A) & СTCTGTCACCTTCAАССTCTTC & ATCTCAGGTTGCATGACTGG \\
\hline Human IFN入1 (IL-29) & CTGACGCTGAAGGTTCTGG & CTGACGCTGAAGGTTCTGG \\
\hline Human IFN $\lambda 3$ (IL-28B) & CTGACGCTGAAGGTTCTGG & ATATGGTGCAGGGTGTGAAG \\
\hline Human IFNB & CTCTGGCAACAGGTAGTAGG & GGAAAGAGCTGTAGTGGAGAAG \\
\hline
\end{tabular}

